Networks of Free Trade Agreements among Heterogeneous Countries

A. Mauleon, H. Song and V. Vannetelbosch

Discussion Paper 2006-29

Département des Sciences Économiques

de l'Université catholique de Louvain 


\title{
Networks of Free Trade Agreements among Heterogeneous Countries*
}

\author{
Ana Mauleon, \\ Huasheng Song, \\ FNRS and CEREC, \\ Zhejiang University. \\ Facultés Universitaires Saint-Louis, \\ and CORE. \\ Vincent Vannetelbosch, \\ FNRS and CORE, \\ Université catholique de Louvain. \\ CORE DISCUSSION PAPER 2006/53
}

\begin{abstract}
The paper examines the formation of free trade agreements as a network formation game. We consider a three-country model in which international trade occurs between economies with imperfectly competitive product markets. Labor markets can be unionized and non-unionized in each country. We show that if all countries are of the same type (all of them are either unionized or non-unionized), the global free trade network is both the unique pairwise stable network and the unique efficient network. If some countries are unionized while others are non-unionized, other networks apart from the global free trade network are likely to be pairwise stable. However, the efficient network is always the global free trade network. Thus, a conflict between stability and efficiency may occur. Moreover, starting from the network in which no country has signed a free trade agreement, all sequences of networks due to continuously profitable deviations do not lead (in most cases) to the global free trade network, even when global free trade is stable.
\end{abstract}

Key words: F15, F16, C70

JEL classification: Free-trade agreements, network formation game, unionization.

\footnotetext{
${ }^{*}$ Ana Mauleon and Vincent Vannetelbosch are Research Associates of the National Fund for Scientific Research (FNRS), Belgium. Vincent Vannetelbosch is Associate Fellow of CEREC, Facultés Universitaires Saint-Louis. We wish to thank Paul Belleflamme, Rafael Moner-Colonques, Jose Sempere-Monerris, Jacques Thisse and Xavier Wauthy for helpful comments and discussions. Corresponding author: Prof. Ana Mauleon, Facultés Universitaires Saint-Louis, Boulevard du Jardin Botanique 43, 1000 Brussels, Belgium (e-mail: mauleon@fusl.ac.be)
} 


\section{Introduction}

The pursuit of bilateral and regional trade agreements in the last decades, has raised the question of whether bilateral trade agreements or multilateral trade negotiations under the auspices of GATT is the most conductive to a movement towards global free trade and a maximization of world welfare. Governments have asserted that bilateral free trade negotiations are compatible with the goal of multilateral trade liberalization, but others (Bhagwati (1993) and Levy (1997)) have questioned whether bilateral arrangements will lead to broader liberalization. Considerable attention has been given to the welfare effects of regional free trade associations and customs unions (see for example Krugman (1991)).

A second set of issues concern the incentives of countries to form regional free trade associations and customs unions, and the strategic stability of particular trading regimes. Krishna (1998) has adopted a political economy approach to show that trade-diverting preferential arrangements are more likely to be supported politically and that such preferential arrangements could critically change domestic incentives so multilateral liberalization that is initially politically feasible could be rendered infeasible by a preferential arrangement. ${ }^{1}$ Contrary to Krishna (1998), Ornelas (2005a) has used an oligopolisticpolitical-economy model where the external tariffs of the members of a free trade agreement, as well as the decision to form free trade agreements, are endogenously determined. He has shown that free trade agreements tend to enhance support for further liberalization at the multilateral level by reducing the role of special interests criteria in governments' trade regime decisions. Adopting a slightly different approach, Yi (1996) has endogenized the formation of the customs union structure, which is a partition of the set of countries. He has shown that the rules of customs union formation are crucial: if open membership is allowed, then the grand coalition (global free trade) is the only stable customs union. However, the grand coalition is not stable under the rule that a union is formed if and only if all potential members agree to its formation. But the restriction to partitions is a strong one indeed if our interest is in bilateral trade agreements, since it rules out situations in which, for example, countries 1 and 2 have a bilateral trade agreement and countries 2 and 3 have a similar agreement but there is no agreement between 1 and $3 .^{2}$ When this occurs, it is not appropriate to view countries 1,2 and 3 as one coalition, and we cannot think of 1 and 2 and 2 and 3 being two distinct coalitions, since this violates the mutual exclusiveness property of coalitions. The theory of networks provides a natural way to

\footnotetext{
${ }^{1}$ Levy (1997), using a median-voter model in a differentiated products-monopolistic competition setting has arrived at similar conclusions: bilateral arrangements can undermine political support for multilateral trade liberalization.

${ }^{2}$ For instance, Israel has bilateral free trade agreements with the United States and the European Community, respectively, but the latter two do not have such an agreement between them.
} 
think of such issues, since it allows for such intransitive relationships, and it allows the study of the nature of trading regimes that are consistent with the incentives of individual countries. $^{3}$

Goyal and Joshi (2005) have been the first investigating the formation of free trade agreements as a network formation game. By assuming that countries are symmetric with respect to the market size and the number of domestic firms they obtain that the process of bilateral trade agreements can generate either a free trade regime or an almost free trade regime. Furusawa and Konishi (2002) have analyzed the trading network generated by countries that trade a numeraire good and a continuum of differentiated industrial commodities. They have shown that, when all countries are symmetric, the global free trade network in which every pair of countries sign a free trade agreement is stable, and it is the unique stable network if industrial commodities are not highly substitutable. However, if countries are asymmetric in the market size and/or in the size of industrial good sector, the global free trade network may not be attained. ${ }^{4}$ The purpose of the present paper is to provide another kind of asymmetry that could impede the formation of a free trade network among countries: the fact that some countries are unionized while others are non-unionized.

The labor market implications of European integration are of considerable importance. Since labor is not very mobile in Europe, the effects of international integration on labor markets are mostly indirect via product market integration. In the literature, product market integration has been interpreted as a reduction in costs associated with international trade: transport costs, tariffs, taxes, information costs about foreign markets, etc. These costs could be divided into fixed costs or start up costs associated with exporting, and variable costs proportional to the level of exports. Huizinga (1993) has shown that a decrease in fixed costs, that implies the move from autarky to fully integrated markets, would increase the degree of competition in the product market and would reduce wages. However, Naylor (1998) has shown that a decrease in variable export costs may give rise to a higher wage since a monopoly union responds by increasing the wage rate to the increased employment's demand. But these works proceed by considering symmetric countries.

In this paper we address the following questions:

\footnotetext{
${ }^{3}$ Strategic models of network formation have been first developed by Jackson and Wolinsky (1996) and Bala and Goyal (2000). Jackson (2003, 2005) provides surveys of models of network formation.

${ }^{4}$ Furusawa and Konishi (2005) have extended their previous analysis by introducing the possibility of transfers between the signatories of free trade agreements. In that case, they have shown that, even if the world consists of fairly asymmetric countries, the global free trade network is stable, and it is the unique stable network unless industrial commodities are highly substitutable.
} 
(i) What is the relationship between the degree of product market integration and the wage level in presence of asymmetries among countries?

(ii) What are the incentives of unionized and non-unionized countries to form free trade agreements and what is the architecture of stable networks of free trade agreements?

(iii) Are individual incentives to form free trade agreements adequate from a social welfare point of view?

To answer these questions we use a model of imperfect competition that could be regarded as a simplified version of the oligopolistic intra-industry trade model of Krishna (1998), in the sense that we assume one firm in each country and identical demand functions. ${ }^{5}$ But we enrich Krishna's model by incorporating the existence of countries of different types (unionized or non-unionized) and by endogenizing the formation of any trading regime. We develop a three-stage game. In stage one, each government decides the bilateral free trade agreements (links) he likes to sign in order to maximize welfare. The collection of pairwise links between countries defines a trading regime (network). In the second stage, given a configuration of free trade agreements, wages are set inside each country either by the union (if the firm is unionized) or by the firm (if the firm is nonunionized). Finally, in the third stage, firms compete in the different markets by choosing quantities. Each firm regards each country as a separate market and chooses the profitmaximizing quantity for each market separately, and on the Cournot assumption that the other firms' outputs in each market are given. We are interested in the network of free trade agreements that emerges in this setting.

A simple way to analyze the networks that one might expect to emerge in the long run is to examine a sort of equilibrium requirement that agents not benefit from altering the structure of the network. A weak version of such condition is the pairwise stability notion defined by Jackson and Wolinsky (1996). A network is pairwise stable if no agent benefits from severing one of their links and no other two agents benefit from adding a link between them, with one benefiting strictly and the other at least weakly. In a threecountry model, there are four possible network architectures: the complete network, the star network, the partially connected network, and the empty network. In the complete network (global free trade) every pair of countries are linked (every pair of countries have signed a free trade agreement). The star network is a network in which there is a "hub"

\footnotetext{
${ }^{5}$ Many studies have given theoretical support to the empirical observation that a large share of international trade is intra-industry, i.e., consists of two-way trade in identical, or similar, products. Monopolistic or imperfect competition plays an important role behind the reason advocated in the explanations (see Anderson, Donsimoni and Gabszewicz (1989) and Cordella (1993)).
} 
country directly linked to every other country, while none of the other countries have a direct link with each other. The partially connected network refers to a configuration in which two countries are linked while the third country is isolated. In the empty network there is no link.

There are two effects when two symmetric countries sign a free trade agreement implying a tariff-free access to their respective markets. First, the foreign firm can enter the domestic market without paying tariffs. It has an ambiguous impact on the social welfare of the home country since it increases domestic competition and thus increases consumers surplus but lowers profits of the own firm from domestic operations as well as collected tariffs. Second, the domestic firm gets greater access to the foreign market. It raises profits of the domestic firm from foreign operations. However, the net impact on the social welfare of the home country is positive. So, any pair of symmetric countries has an incentive to form a bilateral free trade agreement. We find that the complete network is the unique pairwise stable network when either all firms are unionized or all firms are non-unionized. This last result contrasts with Goyal and Joshi (2005) where tariffs remain prohibitively high between countries that do not have a bilateral free trade agreement. ${ }^{6}$ Goyal and Joshi (2005) have obtained that a stable trading network is either a complete network or consists of two components, one component has $N-1$ countries and is complete, and the other component has a single country. In our model, the fact that tariffs are not prohibitive between countries that have not signed a free trade agreement makes consumers, firms and countries prefer the free trade regime. ${ }^{7}$ We also find that the complete network is the efficient network (i.e. the network that maximizes aggregate social welfare) in each of the two symmetric settings. Thus, there is no conflict between stability and efficiency when either all firms are unionized or all firms are non-unionized.

Consider now the formation of a free trade agreement between a unionized country and a non-unionized country. Under unionization, a large share of the profits of the domestic firm goes to the union which diminishes its competitive advantage with respect to the

\footnotetext{
${ }^{6}$ This result also contrasts with Anderson, Donsimoni and Gabszewicz (1989) and with Cordella (1993). While Anderson, Donsimoni and Gabszewicz (1989) have shown that for any given number of firms in each country's industry, there is always at least one of the two countries where firms make higher profits under autarky than under free trade, Cordella (1993) has shown that even if, at the world level, free trade is welfare improving with respect to autarky, it can be the case that some countries are damaged by intra-industry trade liberalization. This happens if the gains of consumers cannot outweigh the losses of producers.

${ }^{7}$ Krishna (1998) has shown that multilateral liberalization that is initially politically feasible could be rendered infeasible by a preferential arrangement. In our model, the fact that countries maximize welfare instead firms' profits and the fact that we endogenize the formation of any trading regime makes stable the global free trade regime.
} 
non-unionized foreign firm. Hence, the positive effect due to greater access to the foreign market is relatively small compared to the large negative effect on profits of the domestic firm in the domestic market. Thus, the overall effect of a bilateral free trade agreement can be negative. This may prevent the unionized country from forming a bilateral free trade agreement with a non-unionized country. We find that when only one country is unionized, the complete network is always pairwise stable, but the partially connected network in which the two non-unionized countries have signed a free trade agreement is also pairwise stable, except for very small values of the cost per unit of the commodity exported (when the initial degree of product market integration is very high). When only one country is non-unionized, the partially connected network in which the two unionized countries have signed a free trade agreement is pairwise stable for small values of the cost per unit of the commodity exported, the star networks in which one of the unionized countries is connected with the other two countries is pairwise stable for intermediates values of the cost per unit of the commodity exported, and the complete network is only pairwise stable for relatively high values of the cost per unit of the commodity exported. However, the complete network is the efficient network in each of these two asymmetric settings. Thus, a conflict between stability and efficiency may occur. Moreover, starting from the network in which no country has signed a free trade agreement, all sequences of networks due to continuously profitable deviations do not lead (in most cases) to the global free trade network, even when global free trade is stable.

Regarding the relationship between the degree of product market integration (measured as the level of variable export costs) and the wage level we find that, in presence of asymmetries among firms, it is no longer true that an increase in product market integration due to a decrease in variable export costs will increase wages as was shown in Naylor (1998). Depending on the strategic position of the own country into the network of free trade agreements, the increase in market integration would increase or reduce the demand for labor. Consequently, the monopoly union will respond by increasing or reducing the wage rate to the increased or reduced demand for labor.

There are other papers that have studied the strategic stability of particular trading regimes. Kennan and Riezman (1990) have constructed a model of customs unions in which countries set optimal tariffs and they showed that if the customs union is big enough it can improve its members' welfare over free trade. Bond and Syropoulos (1996) have proved the instability of a symmetric customs union structure in a pure exchange model of trade among welfare-maximizing countries with CES preferences. But all these contributions take the structure of trading blocks as exogenously given. Finally, other works have focused on 
the welfare effects of preferential free trade associations and customs unions. ${ }^{8}$

The paper is organized as follows. The model is presented in Section 2. In Section 3 we analyze the stability of networks of free trade agreements. In Section 4 we study the efficient networks and we show the conflict between stability and efficiency that arises in the two asymmetric settings. Section 5 concludes the paper.

\section{The model}

We develop a three-stage game in a setting with three countries, each of which has one firm producing some homogeneous good that can sell in the domestic market as well as in each of the foreign markets. A firm's ability to sell in foreign markets, however, depends on the level of import tariffs set by the foreign countries. In the first stage, countries decide the free trade agreements (or links) they are going to establish in order to maximize their respective social welfare level. The collection of pairwise links between the countries defines a network of free trade agreements. If two countries have negotiated a free trade agreement, then each offers the other a tariff-free access to its domestic market; otherwise, each imposes a non-zero tariff $T$ on the imports from the other. Uniform nondiscriminatory tariffs are initially assumed to be applied by all countries on imports from other countries. Firms can be unionized or non-unionized. In the second stage, wages are settled at the firm level by the union or by the firm. Within each country the union or the firm chooses the wage taking as given the wage set in the other countries and taking into account the network of free trade agreements formed at the country level. In the third stage, each firm chooses its output (and hence employment) levels for the separate product markets, taking as given the output decisions of the other firms, the settled wages and the network structure of free trade agreements. We are interested in the network of

\footnotetext{
${ }^{8}$ For instance, Krugman (1991) has demonstrated, in a model with differentiated products, that world welfare is minimized when there are three equal size customs unions. Ethier (1998) has shown that a preferential trade agreement (PTA) between two countries reduces the competitiveness of outside firms in the markets of these two countries, leading to "concession diversion". This effect will undermine bilateral trade agreements and they will be unable to support liberal trading regimes. Bagwell and Staiger (1999) have argued that a free trade agreement (FTA) will impede the implementation of an efficient multilateral trade agreement (though a customs union under certain conditions may not). Deardorff and Stern (1997) have argued that a multiplicity of countries may find it harder to reach consensus on trade issues. They have pointed out that the result of Krugman (1991) is biased against PTAs because the assumption of differentiated products implies that each country will be importing goods from every other country and this creates a strong possibility of trade diversion with consequent reduction in world welfare. Instead, in their model, the incentive to negotiate PTAs is based on comparative advantage. Grafe and Mauleon (2000) have studied the consequences of a private externality on free trade agreements in a general equilibrium framework.
} 
free trade agreements that emerges in this setting. ${ }^{9}$

In a network, countries are the nodes and each link indicates a free trade agreement between the two linked countries. Thus, a network $g$ is simply a list of which pair of countries are linked to each other. If we are considering a pair of countries $i$ and $j$, then $\{i, j\} \in g$ indicates that $i$ and $j$ are linked under the network $g$ and that a free trade agreement between countries $i$ and $j$ has been negotiated. For simplicity, write $i j$ to represent the link $\{i, j\}$, so $i j \in g$ indicates that $i$ and $j$ are linked under the network $g$. The network obtained by adding link $i j$ to an existing network $g$ is denoted $g+i j$ and the network obtained by deleting link $i j$ from an existing network $g$ is denoted $g-i j$. For any network $g$, let $N(g)=\{i \in N \mid \exists j$ such that $i j \in g\}$ be the set of countries which have at least one link (bilateral free trade agreement) in the network $g$. Let $G$ be the set of all possible networks. In this three-country market, there are four possible network architectures (see Figure 1): (i) the complete network, $g^{c}$, in which every pair of countries is linked, (ii) the star network, $g^{s}$, in which there is one country that is linked to the other two countries, (iii) the partially connected network, $g^{p}$, in which two countries have a link and the third country is isolated, and (iv) the empty network, $g^{e}$, in which no country has signed a free trade agreement and therefore there is no link. In the star network, the country which is linked to the other two countries is called the "hub" country, while the other two countries are called the "spoke" countries. Given the importance of the network position of a country, we will denote $g^{s}(i)$ the star network with country $i$ occupying the hub position, and $g^{p}(i j)$ the partial network in which countries $i$ and $j$ are linked.

We denote by $N=\{1,2,3\}$ the set of countries which are connected in a network of free trade agreements. We assume that product demand is linear:

$$
P_{i}=a-b\left(X_{i i}+X_{j i}+X_{k i}\right), \text { for } i, j, k=1,2,3, i \neq j, i \neq k, j \neq k,
$$

where $P_{i}$ is the price of the homogeneous good in country $i, X_{i i}$ is production by firm $i$ for consumption in country $i, X_{j i}$ is production by firm $j$ for consumption in country $i, X_{k i}$ is production by firm $k$ for consumption in country $i, i \in\{1,2,3\}$. Production technology exhibits constant returns to scale with labor as the sole input and is normalized in such a way that $\left(X_{i i}+X_{i j}+X_{i k}\right)=L_{i}$, where $L_{i}$ is labor input of firm $i, i, j, k=1,2,3, i \neq j$, $i \neq k, j \neq k$. The total labor cost to firm $i$ of producing quantity $\left(X_{i i}+X_{i j}+X_{i k}\right)$ is $\left(X_{i i}+X_{i j}+X_{i k}\right) \cdot W_{i}$, where $W_{i}$ is the wage in firm $i$. Let $I_{i j}$ be such that $I_{i j}=1$ if countries $i$ and $j$ have not negotiated a free trade agreement, and $I_{i j}=0$ if countries $i$ and $j$ have negotiated a free trade agreement. Then, for any network $g$, firm $i$ 's profits

\footnotetext{
${ }^{9}$ This oligopolistic perspective has been recently adopted by Krishna (1998) and Ornelas (2005a), and is also consistent with recent empirical evidence that shows that trading blocs that are small in world markets can affect outsiders significantly (see Chang and Winters (2002)).
} 
The empty network

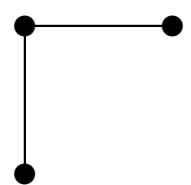

The star network
The partial network

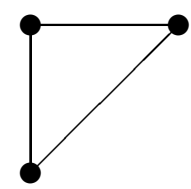

The complete network

Figure 1: Four possible network architectures.

can be written as

$$
\Pi_{i}(g)=\left(P_{i}-W_{i}\right) X_{i i}+\sum_{j \neq i}\left(P_{j}-W_{i}-I_{i j} T\right) X_{i j},
$$

where $T$ is the constant unit trade cost. We restrict parameter $T$ to be $0 \leq T \leq \frac{a}{4}$. By doing so, we concentrate on the more interesting cases in which there is positive trade between two countries that have not negotiated a free trade agreement in at least one of the network architectures. In case the firm is unionized, a risk-neutral union chooses the wage that maximizes the economic rent,

$$
U_{i}(g)=L_{i} \cdot\left(W_{i}-\bar{W}\right)
$$

where $\bar{W}$ is the reservation wage. ${ }^{10}$ Without loss of generality, we assume $\bar{W}=0$. In case the firm is non-unionized, the firm chooses the wage that maximizes profits, i.e., $W_{i}=\bar{W}=0$. For any network $g$, the social welfare of country $i$ is given by

$$
S W_{i}(g)=C S_{i}(g)+\Pi_{i}(g)+C T_{i}(g)+U_{i}(g)
$$

where $C S_{i}(g)=\frac{b}{2}\left(X_{i}\right)^{2}$ with $X_{i}=X_{1 i}+X_{2 i}+X_{3 i}$, is the consumer surplus of country $i, \Pi_{i}(g)$ is the profit of firm $i$ located in country $i, C T_{i}(g)=\sum_{j \neq i} I_{i j} T \cdot X_{i j}$ is the tariff

\footnotetext{
${ }^{10} \mathrm{By}$ tractability, we do not consider a version of the right-to-manage model where unions and firms have bargaining power over wages. However, Jones (1989) and Mauleon and Vannetelbosch (2005) have shown that, if the union bargaining power is not too big, it is optimal for unions that maximize the rents to send to the negotiation table delegates who maximize the wage, and such negotiations may mimic the monopoly-union outcomes where the unions choose their most preferred wages.
} 
revenue of country $i$, and $U_{i}(g)$ are the rents of union $i$. Let $S W(g)$ denote aggregate welfare in network $g$. Then, aggregate social welfare is given by

$$
S W(g)=\sum_{i \in N} S W_{i}(g) .
$$

We have four different situations to be analyzed: (i) all countries are non-unionized; (ii) only one country is unionized and the other two are non-unionized; (iii) two countries are unionized and only one is non-unionized; (iv) all countries are unionized. Before looking for the stability and efficiency of networks of free trade agreements, we derive for each network architecture, the equilibrium wages, quantities produced, profits and social welfare levels. See the appendix for details.

Regarding the relationship between the degree of product market integration (measured as the level of variable export costs) and the wage level we find that, in presence of asymmetries among firms, it is no longer true that an increase in product market integration due to a decrease in variable export costs will increase wages as was shown in Naylor (1998). Depending on the strategic position of the own country into the network of free trade agreements, the increase in market integration would increase or reduce the demand for labor. Consequently, the monopoly union will respond by increasing or reducing the wage rate to the increased or reduced demand for labor. The impact of an increase in market integration on wages in unionized countries is summarized in Table 1 where the symbol "+" means that the impact is positive and that wages increases as a result of higher degrees of market integration, and the symbol "-" means that the impact is negative and that wages decreases as a result of higher degrees of market integration.

$$
\begin{array}{cccc}
\text { empty network } & \text { partial network } & \text { star network } \\
& \text { linked isolated } & \text { spoke hub }
\end{array}
$$

all countries unionized

only one country non-unionized

only one country unionized

$\begin{array}{ccccc}+ & + & + & + & - \\ + & + & + & \pm & - \\ + & \text { nil } & \pm & \pm & -\end{array}$

Table 1: The impact of an increase in market integration on wages in unionized countries

In particular, in case all countries are unionized, an increase in product market integration will increase wages in the empty and partially connected networks. In the star network, an increase in product market integration will increase wages of the firms in the spoke countries and will reduce the wage of the firm in the hub country. ${ }^{11}$ In case only one country is non-unionized (the other two countries are unionized), an increase in product

\footnotetext{
${ }^{11}$ Of course, the wage levels do not depend on the degree of product market integration in the complete network (global free trade).
} 
market integration increases wages in the empty and partially connected networks. In the star network, an increase in product market integration reduces the wage of the unionized firm in the hub country and has an ambiguous impact on the wage of the unionized firm in the spoke country. In case only one country is unionized (the other two countries are non-unionized), an increase in product market integration increases wages in the empty network. In the partially connected network, an increase in product market integration does not modify the wage of the unionized firm in the linked country and has an ambiguous impact on the wage of the unionized firm in the isolated country. In the star network, an increase in product market integration decreases the wage of the unionized firm in the hub country and has an ambiguous impact on the wage of the unionized firm in the spoke country. Thus, we observe that there is no monotonic relationship between the degree of product market integration and the wage rate. While in the empty network greater market integration increases wages, in the partially connected and star networks greater market integration has an ambiguous impact on wages that depend on the strategic position of the own country into the network of free trade agreements and on the degree of product market integration.

\section{$3 \quad$ Stability of free trade networks}

A simple way to analyze the networks that one might expect to emerge in the long run is to examine a sort of equilibrium requirement that agents not benefit from altering the structure of the network. A weak version of such condition is the pairwise stability notion defined by Jackson and Wolinsky (1996). A network is pairwise stable if no agent benefits from severing one of their links and no other two agents benefit from adding a link between them, with one benefiting strictly and the other at least weakly.

Definition 1 A network $g$ is pairwise stable if

(i) for all $i j \in g, S W_{i}(g) \geq S W_{i}(g-i j)$ and $S W_{j}(g) \geq S W_{j}(g-i j)$, and

(ii) for all $i j \notin g$, if $S W_{i}(g)<S W_{i}(g+i j)$ then $S W_{j}(g)>S W_{j}(g+i j)$.

Let us say that $g^{\prime}$ is adjacent to $g$ if $g^{\prime}=g+i j$ or $g^{\prime}=g-i j$ for some $i j$. A network $g^{\prime}$ defeats $g$ if either $g^{\prime}=g-i j$ and $S W_{i}\left(g^{\prime}\right) \geq S W_{i}(g)$, or if $g^{\prime}=g+i j$ with $S W_{i}\left(g^{\prime}\right) \geq S W_{i}(g)$ and $S W_{j}\left(g^{\prime}\right) \geq S W_{j}(g)$ with at least one inequality holding strictly. Pairwise stability is equivalent to saying that a network is pairwise stable if it is not defeated by another (necessarily adjacent) network. This definition of stability is quite 
weak and should be seen as a necessary condition for strategic stability. ${ }^{12}$

We first consider countries' incentives to form bilateral free trade agreements. Lemma 1 tells us that any pair of symmetric countries (with respect to the network position and the unionization) has always incentives to negotiate a free trade agreement.

Lemma 1 Any pair of symmetric countries has always incentives to form a bilateral free trade agreement.

The proof of Lemma 1, as well as all other proofs, can be found in the appendix. There are two effects when two symmetric countries sign a free trade agreement implying a tariff-free access to their respective markets. First, the foreign firm can enter the domestic market without paying tariffs. It has an ambiguous impact on the social welfare of the home country since it increases domestic competition and thus increases consumers surplus but lowers profits of the own firm from domestic operations as well as collected tariffs. Second, the domestic firm gets greater access to the foreign market. It raises profits of the domestic firm from foreign operations. However, the net impact on the social welfare of the home country is positive. So, any pair of symmetric countries has an incentive to form a bilateral free trade agreement.

Lemma 2 tells us that any pair of asymmetric countries, one unionized and one nonunionized but having a similar position in the network, has not always incentives to negotiate a free trade agreement. Moreover, these incentives are smaller the bigger the number of unionized countries.

Lemma 2 ( $i)$ In the asymmetric setting with only one country unionized, the spoke unionized and non-unionized countries in the star network always want to form a bilateral free trade agreement, while the unionized country in the empty network only wants to form a bilateral free trade agreement with one of the non-unionized countries if and only if $T<\frac{15 a}{149}$. (ii) In the asymmetric setting with two countries unionized, the spoke unionized country in the star network only wants to form a bilateral free trade agreement with the non-unionized spoke country if and only if $\frac{63 a}{275}<T \leq \frac{a}{4}$, while any unionized country in the empty network never wants to form a bilateral free trade agreement with the non-unionized country.

\footnotetext{
${ }^{12}$ Pairwise stability only considers deviations on a single link at a time. For instance, it could be that an agent would not benefit from severing any single link but would benefit from severing several links simultaneously, and yet the network would still be pairwise stable. Players cannot be farsighted in the sense that they do not forecast how others might react to their actions. Herings, Mauleon and Vannetelbosch (2004) have proposed a general concept, social rationalizability, that predicts which coalitions or networks are going to emerge among farsighted players.
} 
Under unionization, a large share of the profits of the domestic firm goes to the union which diminishes its competitive advantage with respect to the non-unionized foreign firm. Hence, the positive impact on social welfare of the home country due to greater access to the foreign market can be relatively small compared to the large decrease on profits of the domestic firm in the domestic market. Thus, the net impact on the social welfare of the home country of a bilateral free trade agreement can be negative. This prevents sometimes the unionized country from forming a bilateral free trade agreement with a non-unionized country.

We are interested in the networks of free trade agreements that emerge in four different settings: (i) no firm is unionized, (ii) one of the three firms is unionized, (iii) two of the three firms are unionized and (iv) all firms are unionized. We first study pairwise stable networks when all countries are non-unionized.

Proposition 1 Suppose all countries are non-unionized. The complete network $g^{c}$ is the unique pairwise stable network.

Proposition 1 tells us which networks are pairwise stable when all firms are nonunionized. As shown by Lemma 1, the empty network $g^{e}$ and the star network $g^{s}$ are never stable because two symmetric countries have always incentives to form a bilateral trade agreement. Thus, the complete network $g^{c}$ is always pairwise stable. Moreover, the partial network $g^{p}$ is never stable because the isolated country and any of the two linked countries have incentives to sign a free trade agreement. Proposition 1 shows that if individual countries care about domestic social welfare then the formation of bilateral trade agreements will generate a global free trade regime. In case individual countries care only about domestic consumer surplus then bilateral trade agreements would also generate a global free trade regime. Finally, regarding only domestic profits, the global free trade regime is the unique pairwise stable network. This suggests that, in case of non-unionized firms, firms will have no incentives to lobby against bilateral trade agreements. This result contrasts with the result we obtain when all firms are unionized according to which firms could, in some cases, have incentives to lobby against bilateral trade agreements. This result also contrasts with Goyal and Joshi (2005) where tariffs are prohibitively high between countries that do not have a bilateral free trade agreement. Indeed, given that firm's profit under autarky are higher than in any symmetric trading regime in which every country has a given number of active firms, Goyal and Joshi (2005) have concluded that firms will have incentives to lobby against bilateral free trade agreements. ${ }^{13}$ In our

\footnotetext{
${ }^{13}$ This is the reason why they have obtained the result that a stable trading network is either a complete network or consists of two components, one component has $N-1$ countries and is complete, and the other component has a single country.
} 
model, the fact that tariffs are not prohibitive between countries that have not signed a free trade agreement makes firms also preferring the free trade regime. So, there is no conflict between firms' objectives and social welfare maximizing countries: both countries and firms support the free trade regime.

Belleflamme and Bloch (2004) have analyzed reciprocal market sharing agreements by which firms commit not to enter each other's territory in oligopolistic markets. Trade agreements can be interpreted as the converse of market sharing agreements: trade agreements open up foreign markets by abolishing tariffs whereas market sharing agreements lead to the closure of foreign markets. They have shown that in the presence of transportation costs when selling on a foreign market, only two different collusive networks are pairwise stable in a linear Cournot oligopoly model: the complete network in which any two firms collude, and the empty network in which no pair of firms colludes. But the empty network (that corresponds to our complete network) is only stable for low enough transportation (or tariff) costs. Thus, in their model firms could have incentives to lobby against bilateral free trade agreements.

We now analyze which networks are pairwise stable when one country is unionized and two countries are non-unionized.

Proposition 2 Suppose country $k$ is unionized and countries $i$ and $j$ are non-unionized. (i) If $T \leq \frac{5 a}{167}$, then the complete network $g^{c}$ is the unique pairwise stable network. (ii) If $\frac{5 a}{167}<T \leq \frac{a}{4}$, then the complete network $g^{c}$ and the partially connected network $g^{p}(i j)$ are the only pairwise stable networks.

Proposition 2 shows the pairwise stable networks when the firm of country $k$ is unionized and the firms of countries $i$ and $j$ are non-unionized. As shown by Lemma 1, the empty network $g^{e}$ and the star network $g^{s}(k)$ are never stable because two symmetric nonunionized countries have always incentives to form a bilateral trade agreement. By Lemma 2 , the star networks $g^{s}(i)$ and $g^{s}(j)$ are never pairwise stable because the spoke unionized country and the spoke non-unionized country have incentives to form a bilateral free trade agreement. Thus, the complete network $g^{c}$ is always pairwise stable. By Lemma 2, the partial networks $g^{p}(i k)$ and $g^{p}(j k)$ are not pairwise stable for $\frac{15 a}{149}<T \leq \frac{a}{4}$ because the unionized country would have incentives to delete his link with the non-unionized country. Moreover, for $T \leq \frac{15 a}{149}$, the partial networks $g^{p}(i k)$ and $g^{p}(j k)$ are not pairwise stable because the non-unionized countries have incentives to form a link moving to the star network $g^{s}(i)$ or $g^{s}(j)$. Finally, the partially connected network $g^{p}(i j)$ is pairwise stable if and only if $\frac{5 a}{167}<T \leq \frac{a}{4}$ because the unionized country has no incentives to sign a free trade agreement with any of the linked non-unionized countries. The intuition is the same as the one in Lemma 2. Under unionization, a large share of the profits of the domestic 
firm goes to the union which diminishes its competitive advantage with respect to the non-unionized foreign firm. Hence, the positive effect due to greater access to the foreign market is relatively small compared to the large negative effect on profits of the domestic firm in the domestic market. This prevents the isolated unionized country from forming a bilateral free trade agreement with any of the two linked non-unionized countries.

As in the previous symmetric case, the complete network is pairwise stable for any degree of product market integration (for any $T \leq \frac{a}{4}$ ). This means that once the global free trade regime has been formed it will prevail. But assume that countries start forming bilateral free trade agreements from the empty network. In such case, the formation of a first bilateral free trade agreement between the two non-unionized countries could impede the formation of ulterior bilateral free trade agreements and therefore the constitution of the free trade regime. In the next section we will analyze which pairwise stable networks are likely to be reached from a situation in which no country has signed a free trade agreement (in fact the empty network).

We now analyze which networks are pairwise stable when two countries are unionized and one country is non-unionized.

Proposition 3 Suppose countries $i$ and $j$ are unionized and country $k$ is non-unionized. (i) If $T \leq T^{\prime} \simeq 0.089 a$, then the partially connected network $g^{p}(i j)$ is the unique pairwise stable network. (ii) If $T^{\prime}<T \leq \frac{63 a}{275}$, then the star networks $g^{s}(i)$ and $g^{s}(j)$ are the only pairwise stable networks. (iii) If $\frac{63 a}{275}<T \leq \frac{a}{4}$, then the complete network $g^{c}$ is the unique pairwise stable network.

Proposition 3 tells us which networks are pairwise stable when the firms of countries $i$ and $j$ are unionized and the firm of country $k$ is non-unionized. As shown by Lemma 1, the empty network $g^{e}$ and the star network $g^{s}(k)$ are never stable because two symmetric non-unionized countries have always incentives to form a bilateral trade agreement. By Lemma 2, the partial networks $g^{p}(i k)$ and $g^{p}(j k)$ are never pairwise stable because the unionized country would have incentives to delete his link with the non-unionized country. The star networks $g^{s}(i)$ and $g^{s}(j)$ are not pairwise stable for $\frac{63 a}{275}<T \leq \frac{a}{4}$ because the spoke unionized country and the spoke non-unionized country have incentives to form a bilateral free trade agreement. Thus, the complete network $g^{c}$ is always pairwise stable for $\frac{63 a}{275}<T \leq \frac{a}{4}$. Moreover, the star networks $g^{s}(i)$ and $g^{s}(j)$ are not pairwise stable for $T \leq T^{\prime} \simeq 0.089 a$, because the unionized hub country has incentives to delete his link with the non-unionized spoke country moving to the partial network $g^{p}(i j)$. Then, the star networks $g^{s}(i)$ and $g^{s}(j)$ are pairwise stable if and only if $T^{\prime}<T \leq \frac{63 a}{275}$. Finally, the partial network $g^{p}(i j)$ is pairwise stable if and only if $T \leq T^{\prime} \simeq 0.089 a$. For such 
values of $T$ any unionized country has no incentive either to form a link with the isolated non-unionized country or to delete the link with the other unionized country.

The fact that the partially connected network $g^{p}(i j)$ is pairwise stable only for high enough degrees of product market integration can be explained as follows. Indeed, since the profits of the unionized hub firm are increasing with $T$, the lower the degree of product market integration the greater the incentives of any unionized linked country to form a link with the isolated non-unionized country. Then, for small enough degrees of product market integration the star network $g^{s}(i)$ or $g^{s}(j)$ will be formed. Any of these two star networks is pairwise stable for $T^{\prime}<T \leq \frac{63 a}{275}$. Smaller degrees of product market integration give incentives to the spoke unionized country to form a link with the spoke non-unionized country moving to the complete network. Contrary to the previous cases, the complete network is pairwise stable only for small enough degrees of product market integration, $\frac{63 a}{275}<T \leq \frac{a}{4}$. Indeed, for such values of $T$, the firm of the spoke unionized country prefers not to sell the good in the spoke non-unionized country. The formation of a bilateral free trade agreement between both countries results then advantageous for both of them.

Finally, we analyze which networks are pairwise stable when all countries are unionized.

Proposition 4 Suppose all countries are unionized. The complete network $g^{c}$ is the unique pairwise stable network.

Proposition 4 tells us that the complete network or global free trade is the unique pairwise stable network when all firms are unionized. As shown by Lemma 1, the empty network $g^{e}$ and the star network $g^{s}$ are never stable because two symmetric countries have always incentives to form a bilateral trade agreement. Thus, the complete network $g^{c}$ is always pairwise stable. Indeed, the welfare level of a country in the complete network is independent of $T$. However, the welfare of the spoke countries in the star network is decreasing with $T$. So, it is always better for the spoke countries to form a link. Moreover, the partial network $g^{p}$ is never stable because the isolated country and any of the two linked countries have incentives to sign a free trade agreement. Proposition 4 shows that if individual countries care about domestic social welfare then the formation of bilateral trade agreements makes stable the global free trade regime. In case individual countries care only about domestic consumer surplus then bilateral trade agreements would make stable the global free trade regime. However, regarding only domestic profits, the global free trade regime would be stable only if the constant unit trade cost $T$ is smaller than a certain $T^{\prime \prime}<\frac{a}{4}$; for values of $T$ such that $T^{\prime \prime}<T \leq \frac{a}{4}$, the partially connected network would be the unique pairwise stable network. This suggests that, in some cases, firms would have incentives to lobby against bilateral trade agreements. Finally, notice that the complete network "survives" (in the sense that it remains pairwise stable for some 
values of the external tariffs) the introduction of asymmetries in countries (unionized or non-unionized), and this could be seen as something positive for multilateral trade liberalization.

\section{Efficient networks and dynamic network formation}

We now examine aggregate social welfare under the different networks. Remember that aggregate social welfare $S W(g)$ under a network $g$ is given by $S W(g)=\sum_{i \in N} S W_{i}(g)$. We say that a network $g$ is efficient if and only if $S W(g) \geq S W\left(g^{\prime}\right)$ for all $g^{\prime}$.

Contrary to the case of pairwise stable networks, there is a unique efficient network in any of the four different settings: the complete network $g^{c}$. Moreover, aggregate social welfare is increasing with the number of links.

Proposition 5 In any of the four different settings, the complete network $g^{c}$ is the unique efficient network and aggregate social welfare is increasing with the number of links.

Proposition 5 shows that, in case all firms are non-unionized, there is no conflict between stability and efficiency. The complete network $g^{c}$ is both the unique pairwise stable network and the efficient network. However, when only one country is unionized, a conflict between pairwise stability and efficiency may occur (see Figure 2). Meanwhile the efficient network is always pairwise stable, the reverse is not true since the partially connected network $g^{p}(i j)$ is sometimes pairwise stable but is never efficient. When only one country is non-unionized, a conflict between pairwise stability and efficiency occur (see Figure 3). Indeed, for $T \leq \frac{63 a}{275}$, the efficient network is never pairwise stable and vice versa. Only for $\frac{63 a}{275}<T \leq \frac{a}{4}$, the complete network $g^{c}$ is both the unique pairwise stable network and the efficient network. In case all firms are unionized, there is no conflict between stability and efficiency. The complete network $g^{c}$ is both the unique pairwise stable network and the efficient network.

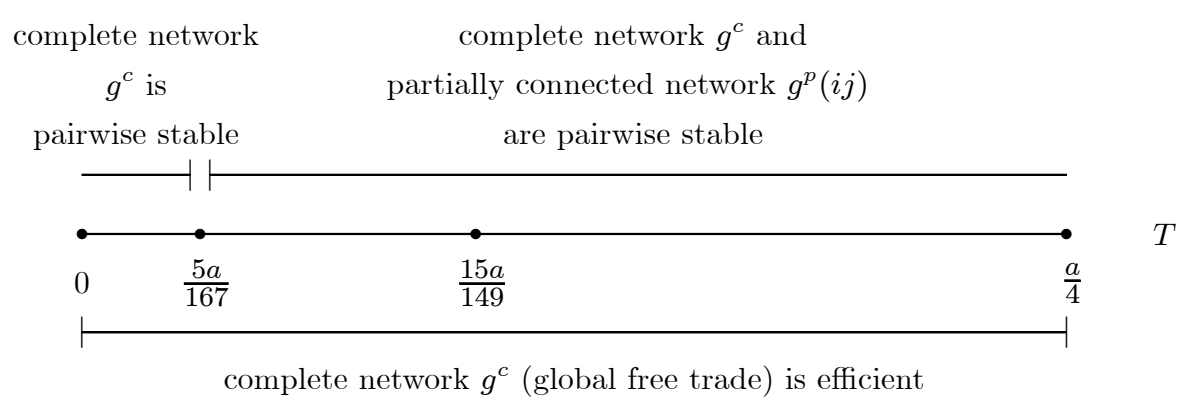

Figure 2: Conflict between stability and efficiency when only country $k$ is unionized. 


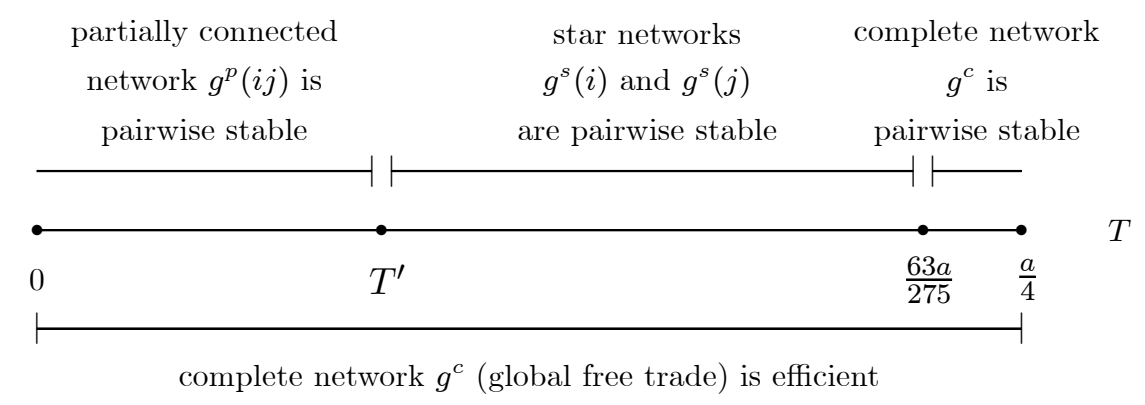

Figure 3: Conflict between stability and efficiency when only country $k$ is non-unionized.

Finally, we explore which pairwise stable networks are likely to be reached from a situation in which no country has signed a free trade agreement (in fact the empty network). Such networks are called stable states. We first define the notions of improving paths and stable states due to Jackson and Watts $(2001,2002)$. An improving path ${ }^{14}$ from a network $g$ to a network $g^{\prime}$ is a finite sequence of networks $g_{1}, \ldots, g_{K}$ with $g_{1}=g$ and $g_{K}=g^{\prime}$ such that for any $k \in\{1, \ldots, K-1\}$ either: (i) $g_{k+1}=g_{k}-i j$ for some $i j$ such that $S W_{i}\left(g_{k}-i j\right)>S W_{i}\left(g_{k}\right)$, or (ii) $g_{k+1}=g_{k}+i j$ for some $i j$ such that $S W_{i}\left(g_{k}+i j\right)>S W_{i}\left(g_{k}\right)$ and $S W_{j}\left(g_{k}+i j\right) \geq S W_{j}\left(g_{k}\right)$. An improving path is thus a sequence of networks that might be observed in a dynamic process where agents are myopically adding and deleting links. ${ }^{15}$ A network $g$ is a stable state if it is pairwise stable and there exists an improving path connecting the empty network to $g$.

In case of symmetric countries, the complete network $g^{c}$ is the unique stable state. However, once countries are asymmetric, a conflict between efficiency and stable states is likely to occur.

Corollary 1 Suppose country $k$ is unionized, countries $i$ and $j$ are non-unionized. ( $i$ ) If $T \leq \frac{5 a}{167}$, then the complete network $g^{c}$ is the unique stable state. (ii) If $\frac{5 a}{167}<T \leq \frac{15 a}{149}$, then the complete network $g^{c}$ and the partially connected network $g^{p}(i j)$ are the stable states. (iii) If $\frac{15 a}{149}<T \leq \frac{a}{4}$, then the partially connected network $g^{p}(i j)$ is the unique stable state.

\footnotetext{
${ }^{14}$ An improving path is a sequence of networks that can emerge when agents form or sever links based on the improvement the resulting network offers relative to the current network. Each network in the sequence differs by one link from the previous one. If a link is added, then the two agents involved must both agree to its addition, with at least one of the two strictly benefiting from the addition of the link. If a link is deleted, then it must be that at least one of the two agents involved in the link strictly benefits from its deletion.

${ }^{15} \mathrm{~A}$ network is pairwise stable if and only if it has no improving paths emanating from it.
} 
Corollary 2 Suppose countries $i$ and $j$ are unionized, country $k$ is non-unionized. (i) If $T \leq T^{\prime} \simeq 0.089 a$, then the partially connected network $g^{p}(i j)$ is the unique stable state. (ii) If $T^{\prime}<T \leq \frac{63 a}{275}$, then the star networks $g^{s}(i)$ and $g^{s}(j)$ are the stable states. (iii) If $\frac{63 a}{275}<T \leq \frac{a}{4}$, then the complete network $g^{c}$ is the unique stable state.

We observe that, starting from the network in which no country has signed a free trade agreement, sequences of networks due to continuously profitable deviations will not lead in most cases to the global free trade network (complete network), even when global free trade is pairwise stable. Remember that the global free trade network $g^{c}$ is the efficient one. Thus, the conflict between stable states and efficient ones is far from being negligible when countries are asymmetric.

\section{Concluding remarks}

In this paper we have examined the formation of free trade agreements as a network formation game. We have considered a three-country model in which international trade occurs between economies with imperfectly competitive product markets. Labor markets can be unionized and non-unionized in each country. We have shown that if all countries are of the same type (all of them are either unionized or non-unionized), the global free trade network is both the unique pairwise stable network and the unique efficient network. If some countries are unionized while others are non-unionized, other networks apart from the global free trade network are likely to be pairwise stable. ${ }^{16}$ However, the efficient network is always the global free trade network. Thus, a conflict between stability and efficiency may occur. Moreover, starting from the network in which no country has signed a free trade agreement, all sequences of networks due to continuously profitable deviations do not lead (in most cases) to the global free trade network, even when global free trade is stable. Finally, no monotonic relationship between the degree of product market integration and the wage rate has been found.

Some extensions may be worthwhile. First, it would be interesting to treat the trade regime, as well as the choice of external tariffs under each trade regime, as endogenous decisions. We have concentrated on the incentives for liberalization on a non-discriminatory basis by assuming that uniform non-discriminatory tariffs are applied by all countries on

\footnotetext{
${ }^{16}$ The scope of the three-country analysis presented here is limited in that it does not include such possibilities as, for instance, the formation of two free trade agreements between two unionized and two non-unionized countries, respectively, where further liberalization implies a symmetric elimination of preferential access in both bilateral arrangements. Thus, this unbalanced preferentialism (apart from the existence of different types of countries) can also create problems per se for further liberalization.
} 
imports from other countries. We have also considered that external tariffs remain constant with the formation of a free trade agreement. Since the World Trade Organization precludes members of free trade areas from using these arrangements as a justification to bypass their previous tariff bindings and raise external tariffs, one could allow for the possibility that external tariffs decrease with the formation of a free trade agreement. Second, it would be interesting to consider other objective functions for the countries. Krishna (1998) has shown that multilateral liberalization that is initially politically feasible could be rendered infeasible by a preferential arrangement when the external tariffs to non-members are fixed and countries maximize domestic firms' profits. Ornelas (2005b) has extended Krishna's framework by endogenizing external tariffs to non-members and assuming that governments maximize a welfare function that assigns a higher weight to profits. He has shown that free trade agreements become then pure trade creating devices (instead of trade diverting devices) that benefit non-member countries. As a result, the free trade agreement may induce the non-member countries to withdraw their support to a multilateral trade agreement. But Ornelas (2005b) has only compared the welfare of non-member countries in the presence of a free trade agreement (our partial network), with their welfare in a multilateral trade agreement (our complete network), without considering the possibility of any other trading regime (as our star network). Thus, it would be very interesting to study the robustness of Krishna (1998) and Ornelas (2005b) results when trading regimes are endogenized.

\section{Acknowledgments}

Financial support from Spanish Ministerio de Ciencia y Tecnología under the project BEC 2003-02084, support from the Belgian French Community's program Action de Recherches Concertée 03/08-302 and 05/10-331 (UCL) and support of a SSTC grant from the Belgian Federal government under the IAP contract $5 / 26$ are gratefully acknowledged.

This paper presents research results of the Belgian Program on Interuniversity Poles of Attraction initiated by the Belgian State, Prime Minister's Office, Science Policy Programming. 


\section{Appendix A: All countries are non-unionized}

The empty network.

$$
\begin{aligned}
\Pi_{i}^{*}\left(g^{e}\right) & =\frac{3 a^{2}-4 a T+12 T^{2}}{16 b}, C S_{i}^{*}\left(g^{e}\right)=\frac{(3 a-2 T)^{2}}{32 b}, C T_{i}^{*}\left(g^{e}\right)=\frac{(a-2 T) T}{2 b} \\
S W_{i}^{*}\left(g^{e}\right) & =\frac{(3 a-2 T)(5 a+2 T)}{32 b}, S W^{*}\left(g^{e}\right)=\frac{3(3 a-2 T)(5 a+2 T)}{32 b}
\end{aligned}
$$

The partially connected network.

For a linked country:

$$
\begin{aligned}
\Pi_{i}^{*}\left(g^{p}\right) & =\frac{3 a^{2}+6 T^{2}}{16 b}, C S_{i}^{*}\left(g^{p}\right)=\frac{(3 a-T)^{2}}{32 b}, C T_{i}^{*}\left(g^{p}\right)=\frac{(a-3 T) T}{4 b} \\
S W_{i}^{*}\left(g^{p}\right) & =\frac{15 a^{2}+2 a T-11 T^{2}}{32 b}
\end{aligned}
$$

For an isolated country:

$$
\begin{aligned}
\Pi_{i}^{*}\left(g^{p}\right) & =\frac{3 a^{2}-8 a T+22 T^{2}}{16 b}, C S_{i}^{*}\left(g^{p}\right)=\frac{(3 a-2 T)^{2}}{32 b}, C T_{i}^{*}\left(g^{p}\right)=\frac{(a-2 T) T}{2 b} \\
S W_{i}^{*}\left(g^{p}\right) & =\frac{15 a^{2}-12 a T+16 T^{2}}{32 b}
\end{aligned}
$$

and the global welfare is

$$
S W^{*}\left(g^{p}\right)=\frac{45 a^{2}-8 a T-6 T^{2}}{32 b}
$$

The star network.

For a hub country:

$$
\begin{aligned}
\Pi_{i}^{*}\left(g^{s}\right) & =\frac{3 a^{2}+4 a T+2 T^{2}}{16 b}, C S_{i}^{*}\left(g^{s}\right)=\frac{9 a^{2}}{32 b}, C T_{i}^{*}\left(g^{s}\right)=0 \\
S W_{i}^{*}\left(g^{s}\right) & =\frac{15 a^{2}+8 a T+4 T^{2}}{32 b}
\end{aligned}
$$

For a spoke country:

$$
\begin{aligned}
\Pi_{i}^{*}\left(g^{s}\right) & =\frac{3 a^{2}-4 a T+10 T^{2}}{16 b}, C S_{i}^{*}\left(g^{s}\right)=\frac{(3 a-T)^{2}}{32 b}, C T_{i}^{*}\left(g^{s}\right)=\frac{(a-3 T) T}{4 b} \\
S W_{i}^{*}\left(g^{s}\right) & =\frac{15 a^{2}-6 a T-3 T^{2}}{32 b}
\end{aligned}
$$

and the global welfare is

$$
S W^{*}\left(g^{s}\right)=\frac{45 a^{2}-4 a T-2 T^{2}}{32 b}
$$

The complete network.

$$
\Pi_{i}^{*}\left(g^{c}\right)=\frac{3 a^{2}}{16 b}, C S_{i}^{*}\left(g^{c}\right)=\frac{9 a^{2}}{32 b}, C T_{i}^{*}\left(g^{c}\right)=0, S W_{i}^{*}\left(g^{c}\right)=\frac{15 a^{2}}{32 b}, S W^{*}\left(g^{c}\right)=\frac{45 a^{2}}{32 b}
$$




\section{Appendix B: One country is unionized, two countries are non-unionized}

The empty network.

For the unionized country:

$$
\begin{aligned}
U_{i}^{*}\left(g^{e}\right) & =\frac{(3 a-2 T)^{2}}{144 b}, W_{i}^{*}\left(g^{e}\right)=\frac{3 a-2 T}{18}, \Pi_{i}^{*}\left(g^{e}\right)=\frac{3 a^{2}-4 a T+44 T^{2}}{64 b} \\
C S_{i}^{*}\left(g^{e}\right) & =\frac{289(3 a-2 T)^{2}}{10368 b}, C T_{i}^{*}\left(g^{e}\right)=\frac{(21 a-38 T) T}{36 b} \\
S W_{i}^{*}\left(g^{e}\right) & =\frac{(3 a-2 T)(1245 a+1186 T)}{10368 b}
\end{aligned}
$$

For a non-unionized country:

$$
\begin{aligned}
\Pi_{i}^{*}\left(g^{e}\right) & =\frac{441 a^{2}-588 a T+1348 T^{2}}{1728 b}, C S_{i}^{*}\left(g^{e}\right)=\frac{289(3 a-2 T)^{2}}{10368 b} \\
C T_{i}^{*}\left(g^{e}\right) & =\frac{(15 a-34 T) T}{36 b}, S W_{i}^{*}\left(g^{e}\right)=\frac{(3 a-2 T)(1749 a+274 T)}{10368 b}
\end{aligned}
$$

and the global welfare is

$$
S W^{*}\left(g^{e}\right)=\frac{17(3 a-2 T)(93 a+34 T)}{3456 b}
$$

The partially connected network.

Suppose the isolated country is non-unionized. For a linked unionized country:

$$
\begin{aligned}
U_{i}^{*}\left(g^{p}\right) & =\frac{a^{2}}{16 b}, W_{i}^{*}\left(g^{p}\right)=\frac{a}{6}, \Pi_{i}^{*}\left(g^{p}\right)=\frac{3\left(a^{2}+8 T^{2}\right)}{64 b}, C S_{i}^{*}\left(g^{p}\right)=\frac{(17 a-6 T)^{2}}{1152 b} \\
C T_{i}^{*}\left(g^{p}\right) & =\frac{(7 a-18 T) T}{24 b}, S W_{i}^{*}\left(g^{p}\right)=\frac{415 a^{2}+132 a T-396 T^{2}}{1152 b}
\end{aligned}
$$

For a linked non-unionized country:

$$
\begin{aligned}
\Pi_{i}^{*}\left(g^{p}\right) & =\frac{49 a^{2}+72 T^{2}}{192 b}, C S_{i}^{*}\left(g^{p}\right)=\frac{(17 a-6 T)^{2}}{1152 b}, C T_{i}^{*}\left(g^{p}\right)=\frac{(7 a-18 T) T}{24 b} \\
S W_{i}^{*}\left(g^{p}\right) & =\frac{11\left(53 a^{2}+12 a T-36 T^{2}\right)}{1152 b}
\end{aligned}
$$

For the isolated non-unionized country:

$$
\begin{aligned}
\Pi_{i}^{*}\left(g^{p}\right) & =\frac{49 a^{2}-112 a T+264 T^{2}}{192 b}, C S_{i}^{*}\left(g^{p}\right)=\frac{(17 a-12 T)^{2}}{1152 b}, C T_{i}^{*}\left(g^{p}\right)=\frac{(5 a-12 T) T}{12 b} \\
S W_{i}^{*}\left(g^{p}\right) & =\frac{583 a^{2}-600 a T+576 T^{2}}{1152 b}
\end{aligned}
$$

and the global welfare is

$$
S W^{*}\left(g^{p}\right)=\frac{527 a^{2}-112 a T-72 T^{2}}{384 b}
$$


When the isolated country is unionized, we should distinguish two cases.

[Case 1] $T \leq \frac{3 a}{14}$

For a linked non-unionized country:

$$
\begin{aligned}
\Pi_{i}^{*}\left(g^{p}\right) & =\frac{441 a^{2}-168 a T+664 T^{2}}{1728 b}, C S_{i}^{*}\left(g^{p}\right)=\frac{(51 a-14 T)^{2}}{10368 b}, C T_{i}^{*}\left(g^{p}\right)=\frac{(3 a-14 T) T}{24 b} \\
S W_{i}^{*}\left(g^{p}\right) & =\frac{5247 a^{2}-1140 a T-1868 T^{2}}{10368 b}
\end{aligned}
$$

For the isolated unionized country:

$$
\begin{aligned}
U_{i}^{*}\left(g^{p}\right) & =\frac{(3 a-4 T)^{2}}{144 b}, \Pi_{i}^{*}\left(g^{p}\right)=\frac{3 a^{2}-8 a T+72 T^{2}}{64 b}, C S_{i}^{*}\left(g^{p}\right)=\frac{(51 a-32 T)^{2}}{10368 b} \\
W_{i}^{*}\left(g^{p}\right) & =\frac{3 a-4 T}{18}, C T_{i}^{*}\left(g^{p}\right)=\frac{(21 a-40 T) T}{36 b}, S W_{i}^{*}\left(g^{p}\right)=\frac{5\left(747 a^{2}-48 a T+464 T^{2}\right)}{10368 b}
\end{aligned}
$$

and the global welfare is

$$
S W^{*}\left(g^{p}\right)=\frac{4743 a^{2}-840 a T-472 T^{2}}{3456 b}
$$

[Case 2] $\frac{3 a}{14}<T \leq \frac{a}{4}$. Then, $X_{i j}^{*}\left(g^{p}\right)=X_{i k}^{*}\left(g^{p}\right)=0, i \neq j, i \neq k$, when $i$ denotes the unionized spoke country.

For a linked non-unionized country:

$$
\begin{aligned}
\Pi_{i}^{*}\left(g^{p}\right) & =\frac{177 a^{2}-140 a T+100 T^{2}}{576 b}, C S_{i}^{*}\left(g^{p}\right)=\frac{2 a^{2}}{9 b}, C T_{i}^{*}\left(g^{p}\right)=0 \\
S W_{i}^{*}\left(g^{p}\right) & =\frac{5\left(61 a^{2}-28 a T+20 T^{2}\right)}{576 b}
\end{aligned}
$$

For the isolated unionized country:

$$
\begin{aligned}
U_{i}^{*}\left(g^{p}\right) & =\frac{(a+2 T)^{2}}{48 b}, W_{j}^{*}\left(g^{p}\right)=\frac{a+2 T}{6}, \Pi_{i}^{*}\left(g^{p}\right)=\frac{(a+2 T)^{2}}{64 b}, C S_{i}^{*}\left(g^{p}\right)=\frac{(17 a-14 T)^{2}}{1152 b} \\
C T_{i}^{*}\left(g^{p}\right) & =\frac{(7 a-10 T) T}{12 b}, S W_{i}^{*}\left(g^{p}\right)=\frac{(331 a-298 T)(a+2 T)}{1152 b}
\end{aligned}
$$

and the global welfare is

$$
S W^{*}\left(g^{p}\right)=\frac{(33 a-14 T)(47 a+14 T)}{1152 b}
$$

\section{The star network.}

Suppose the hub country is unionized. For the unionized hub country:

$$
\begin{aligned}
U_{i}^{*}\left(g^{s}\right) & =\frac{(3 a+2 T)^{2}}{144 b}, W_{i}^{*}\left(g^{s}\right)=\frac{3 a+2 T}{18}, \Pi_{i}^{*}\left(g^{s}\right)=\frac{3 a^{2}+4 a T+4 T^{2}}{64 b} \\
C S_{i}^{*}\left(g^{s}\right) & =\frac{(51 a-2 T)^{2}}{10368 b}, C T_{i}^{*}\left(g^{s}\right)=0, S W_{i}^{*}\left(g^{s}\right)=\frac{3735 a^{2}+1308 a T+940 T^{2}}{10368 b}
\end{aligned}
$$


For a non-unionized spoke country:

$$
\begin{aligned}
\Pi_{i}^{*}\left(g^{s}\right) & =\frac{7\left(63 a^{2}-60 a T+148 T^{2}\right)}{1728 b}, C S_{i}^{*}\left(g^{s}\right)=\frac{(51 a-20 T)^{2}}{10368 b}, C T_{i}^{*}\left(g^{s}\right)=\frac{(21 a-52 T) T}{72 b} \\
S W_{i}^{*}\left(g^{s}\right) & =\frac{5247 a^{2}-1536 a T-872 T^{2}}{10368 b}
\end{aligned}
$$

and the global welfare is:

$$
S W^{*}\left(g^{s}\right)=\frac{4743 a^{2}-588 a T-268 T^{2}}{3456 b}
$$

When the hub country is non-unionized, we should distinguish two cases.

[Case 1] $T \leq \frac{3 a}{16}$

For the unionized spoke country:

$$
\begin{aligned}
U_{i}^{*}\left(g^{s}\right) & =\frac{(3 a-2 T)^{2}}{144 b}, W_{i}^{*}\left(g^{s}\right)=\frac{3 a-2 T}{18}, \Pi_{i}^{*}\left(g^{s}\right)=\frac{3 a^{2}-4 a T+36 T^{2}}{64 b} \\
C S_{i}^{*}\left(g^{s}\right) & =\frac{(51 a-16 T)^{2}}{10368 b}, C T_{i}^{*}\left(g^{s}\right)=\frac{7 T(3 a-8 T)}{72 b}, S W_{i}^{*}\left(g^{s}\right)=\frac{3735 a^{2}-120 a T-1688 T^{2}}{10368 b}
\end{aligned}
$$

For the non-unionized hub country:

$$
\begin{aligned}
\Pi_{i}^{*}\left(g^{s}\right) & =\frac{\left.441 a^{2}+420 a T+172 T^{2}\right)}{1728 b}, C S_{i}^{*}\left(g^{s}\right)=\frac{(51 a+2 T)^{2}}{10368 b}, C T_{i}^{*}\left(g^{s}\right)=0 \\
S W_{i}^{*}\left(g^{s}\right) & =\frac{5247 a^{2}+2724 a T+1036 T^{2}}{10368 b}
\end{aligned}
$$

For the non-unionized spoke country:

$$
\begin{aligned}
\Pi_{i}^{*}\left(g^{s}\right) & =\frac{\left.441 a^{2}-588 a T+1132 T^{2}\right)}{1728 b}, C S_{i}^{*}\left(g^{s}\right)=\frac{(51 a-16 T)^{2}}{10368 b} \\
C T_{i}^{*}\left(g^{s}\right) & =\frac{(3 a-16 T) T}{24 b}, S W_{i}^{*}\left(g^{s}\right)=\frac{5247 a^{2}-3864 a T+136 T^{2}}{10368 b}
\end{aligned}
$$

and the global welfare is

$$
S W^{*}\left(g^{s}\right)=\frac{4743 a^{2}-420 a T-172 T^{2}}{3456 b}
$$

[Case 2] $\frac{3 a}{16}<T \leq \frac{a}{4}$. Then, $X_{i k}^{*}\left(g^{s}(j)\right)=0, i \neq k$, when $i$ denotes the unionized country.

For the unionized spoke country:

$$
\begin{aligned}
U_{i}^{*}\left(g^{s}\right) & =\frac{(2 a+T)^{2}}{96 b}, W_{i}^{*}\left(g^{s}\right)=\frac{2 a+T}{12}, \Pi_{i}^{*}\left(g^{s}\right)=\frac{4 a^{2}+4 a T+5 T^{2}}{128 b} \\
C S_{i}^{*}\left(g^{s}\right) & =\frac{(34 a-13 T)^{2}}{4608 b}, C T_{i}^{*}\left(g^{s}\right)=\frac{7 T(2 a-5 T)}{48 b}, S W_{i}^{*}\left(g^{s}\right)=\frac{1492 a^{2}+796 a T-2963 T^{2}}{4608 b}
\end{aligned}
$$

For the non-unionized hub country:

$$
\begin{aligned}
\Pi_{i}^{*}\left(g^{s}\right) & =\frac{\left.324 a^{2}+196 a T+85 T^{2}\right)}{1152 b}, C S_{i}^{*}\left(g^{s}\right)=\frac{(34 a-T)^{2}}{4608 b}, C T_{i}^{*}\left(g^{s}\right)=0 \\
S W_{i}^{*}\left(g^{s}\right) & =\frac{2452 a^{2}+716 a T+341 T^{2}}{4608 b}
\end{aligned}
$$


For the non-unionized spoke player:

$$
\begin{aligned}
\Pi_{i}^{*}\left(g^{s}\right) & =\frac{\left.324 a^{2}-476 a T+613 T^{2}\right)}{1152 b}, C S_{i}^{*}\left(g^{s}\right)=\frac{2 a^{2}}{9 b}, C T_{i}^{*}\left(g^{s}\right)=0 \\
S W_{i}^{*}\left(g^{s}\right) & =\frac{580 a^{2}-476 a T+613 T^{2}}{1152 b}
\end{aligned}
$$

and the global welfare is

$$
S W^{*}\left(g^{s}\right)=\frac{3132 a^{2}-196 a T-85 T^{2}}{2304 b}
$$

The complete network.

For the unionized country:

$$
\begin{aligned}
U_{i}^{*}\left(g^{c}\right) & =\frac{a^{2}}{16 b}, W_{i}^{*}\left(g^{c}\right)=\frac{a}{6}, \Pi_{i}^{*}\left(g^{c}\right)=\frac{3 a^{2}}{64 b}, C S_{i}^{*}\left(g^{c}\right)=\frac{289 a^{2}}{1152 b}, C T_{i}^{*}\left(g^{c}\right)=0 \\
S W_{i}^{*}\left(g^{c}\right) & =\frac{415 a^{2}}{1152 b}
\end{aligned}
$$

For the non-unionized country:

$$
\Pi_{i}^{*}\left(g^{c}\right)=\frac{49 a^{2}}{192 b}, C S_{i}^{*}\left(g^{c}\right)=\frac{289 a^{2}}{1152 b}, C T_{i}^{*}\left(g^{c}\right)=0, S W_{i}^{*}\left(g^{c}\right)=\frac{583 a^{2}}{1152 b}
$$

and the global welfare is

$$
S W^{*}\left(g^{c}\right)=\frac{527 a^{2}}{384 b}
$$

\section{Appendix C: Two countries are unionized, one is non-unionized}

The empty network.

For the unionized country:

$$
\begin{aligned}
U_{i}^{*}\left(g^{e}\right) & =\frac{(3 a-2 T)^{2}}{100 b}, W_{i}^{*}\left(g^{e}\right)=\frac{3 a-2 T}{15}, \Pi_{i}^{*}\left(g^{e}\right)=\frac{81 a^{2}-108 a T+836 T^{2}}{1200 b} \\
C S_{i}^{*}\left(g^{e}\right) & =\frac{169(3 a-2 T)^{2}}{7200 b}, C T_{i}^{*}\left(g^{e}\right)=\frac{(a-2 T) T}{2 b}, S W_{i}^{*}\left(g^{e}\right)=\frac{(3 a-2 T)(177 a+122 T)}{1440 b}
\end{aligned}
$$

For the non-unionized country:

$$
\begin{aligned}
\Pi_{i}^{*}\left(g^{e}\right) & =\frac{147 a^{2}-196 a T+332 T^{2}}{400 b}, C S_{i}^{*}\left(g^{e}\right)=\frac{169(3 a-2 T)^{2}}{7200 b}, \\
C T_{i}^{*}\left(g^{e}\right) & =\frac{(9 a-26 T) T}{30 b}, S W_{i}^{*}\left(g^{e}\right)=\frac{(1389 a-206 T)(3 a-2 T)}{7200 b}
\end{aligned}
$$

and the global welfare is

$$
S W^{*}\left(g^{e}\right)=\frac{13(3 a-2 T)(81 a+26 T)}{2400 b}
$$


The partially connected network.

Suppose the isolated country is unionized. For the linked unionized country:

$$
\begin{aligned}
U_{i}^{*}\left(g^{p}\right) & =\frac{(21 a-4 T)^{2}}{4900 b}, W_{i}^{*}\left(g^{p}\right)=\frac{a}{5}-\frac{4 T}{105}, \Pi_{i}^{*}\left(g^{p}\right)=\frac{9\left(147 a^{2}-56 a T+822 T^{2}\right)}{19600 b} \\
C S_{i}^{*}\left(g^{p}\right) & =\frac{(39 a-11 T)^{2}}{7200 b}, C T_{i}^{*}\left(g^{p}\right)=\frac{(63 a-247 T) T}{420 b} \\
S W_{i}^{*}\left(g^{p}\right) & =\frac{3717 a^{2}-294 a T-1921 T^{2}}{10080 b}
\end{aligned}
$$

For the isolated unionized country:

$$
\begin{aligned}
U_{i}^{*}\left(g^{p}\right) & =\frac{9(7 a-8 T)^{2}}{4900 b}, W_{i}^{*}\left(g^{p}\right)=\frac{7 a-8 T}{35}, \Pi_{i}^{*}\left(g^{p}\right)=\frac{3969 a^{2}-9072 a T+66434 T^{2}}{58800 b} \\
C S_{i}^{*}\left(g^{p}\right) & =\frac{169(3 a-2 T)^{2}}{7200 b}, C T_{i}^{*}\left(g^{p}\right)=\frac{(21 a-46 T) T}{42 b} \\
S W_{i}^{*}\left(g^{p}\right) & =\frac{3717 a^{2}-1428 a T+2480 T^{2}}{10080 b}
\end{aligned}
$$

For the linked non-unionized country:

$$
\begin{aligned}
\Pi_{i}^{*}\left(g^{p}\right) & =\frac{441 a^{2}-168 a T+466 T^{2}}{1200 b}, C S_{i}^{*}\left(g^{p}\right)=\frac{(39 a-11 T)^{2}}{7200 b} \\
C T_{i}^{*}\left(g^{p}\right) & =\frac{(63 a-247 T) T}{420 b}, S W_{i}^{*}\left(g^{p}\right)=\frac{29169 a^{2}-5502 a T-9221 T^{2}}{50400 b}
\end{aligned}
$$

and the global welfare is

$$
S W^{*}\left(g^{p}\right)=\frac{1053 a^{2}-224 a T-102 T^{2}}{800 b}
$$

Suppose the isolated country is non-unionized. For the linked unionized country:

$$
\begin{aligned}
U_{i}^{*}\left(g^{p}\right) & =\frac{9 a^{2}}{100 b}, W_{i}^{*}\left(g^{p}\right)=\frac{a}{5}, \Pi_{i}^{*}\left(g^{p}\right)=\frac{3\left(9 a^{2}+50 T^{2}\right)}{400 b}, C S_{i}^{*}\left(g^{p}\right)=\frac{(13 a-5 T)^{2}}{800 b} \\
C T_{i}^{*}\left(g^{p}\right) & =\frac{(7 a-15 T) T}{20 b}, S W_{i}^{*}\left(g^{p}\right)=\frac{59 a^{2}+30 a T-55 T^{2}}{160 b}
\end{aligned}
$$

For the isolated non-unionized country:

$$
\begin{aligned}
\Pi_{i}^{*}\left(g^{p}\right) & =\frac{147 a^{2}-280 a T+550 T^{2}}{400 b}, C S_{i}^{*}\left(g^{p}\right)=\frac{(13 a-10 T)^{2}}{800 b} \\
C T_{i}^{*}\left(g^{p}\right) & =\frac{(3 a-10 T) T}{10 b}, S W_{i}^{*}\left(g^{p}\right)=\frac{463 a^{2}-580 a T+400 T^{2}}{800 b}
\end{aligned}
$$

and the global welfare is

$$
S W^{*}\left(g^{p}\right)=\frac{1053 a^{2}-280 a T-150 T^{2}}{800 b}
$$

\section{The star network.}

Suppose the hub country is non-unionized. We distinguish two cases. 
[Case 1] $T \leq \frac{9 a}{41}$

For the unionized spoke country:

$$
\begin{aligned}
U_{i}^{*}\left(g^{s}\right) & =\frac{(3 a-2 T)^{2}}{100 b}, W_{i}^{*}\left(g^{s}\right)=\frac{3 a-2 T}{15}, \Pi_{i}^{*}\left(g^{s}\right)=\frac{81 a^{2}-108 a T+686 T^{2}}{1200 b} \\
C S_{i}^{*}\left(g^{s}\right) & =\frac{(39 a-11 T)^{2}}{7200 b}, C T_{i}^{*}\left(g^{s}\right)=\frac{(9 a-41 T) T}{60 b}, S W_{i}^{*}\left(g^{s}\right)=\frac{531 a^{2}-258 a T-79 T^{2}}{1440 b}
\end{aligned}
$$

For the non-unionized hub country:

$$
\begin{aligned}
\Pi_{i}^{*}\left(g^{s}\right) & =\frac{441 a^{2}+252 a T+86 T^{2}}{1200 b}, C S_{i}^{*}\left(g^{s}\right)=\frac{(39 a+4 T)^{2}}{7200 b}, C T_{i}^{*}\left(g^{s}\right)=0 \\
S W_{i}^{*}\left(g^{s}\right) & =\frac{4167 a^{2}+1824 a T+532 T^{2}}{7200 b}
\end{aligned}
$$

and the global welfare is

$$
S W^{*}\left(g^{s}\right)=\frac{3159 a^{2}-252 a T-86 T^{2}}{2400 b}
$$

[Case 2] $\frac{9 a}{41}<T \leq \frac{a}{4}$. Then, $X_{i j}^{*}\left(g^{s}\right)=X_{j i}^{*}\left(g^{s}\right)=0, i \neq j$, when $i$ and $j$ are the unionized countries.

For the unionized spoke country:

$$
\begin{aligned}
U_{i}^{*}\left(g^{s}\right) & =\frac{833 a^{2}}{11532 b}, W_{i}^{*}\left(g^{s}\right)=\frac{7 a}{31}, \Pi_{i}^{*}\left(g^{s}\right)=\frac{7225 a^{2}}{138384 b} \\
C S_{i}^{*}\left(g^{s}\right) & =\frac{3025 a^{2}}{17298 b}, C T_{i}^{*}\left(g^{s}\right)=0, S W_{i}^{*}\left(g^{s}\right)=\frac{13807 a^{2}}{46128 b}
\end{aligned}
$$

For the non-unionized hub country:

$$
\Pi_{i}^{*}\left(g^{s}\right)=\frac{64433 a^{2}}{138384 b}, C S_{i}^{*}\left(g^{s}\right)=\frac{6241 a^{2}}{30752 b}, C T_{i}^{*}\left(g^{s}\right)=0, S W_{i}^{*}\left(g^{s}\right)=\frac{185035 a^{2}}{276768 b}
$$

and the global welfare is

$$
S W^{*}\left(g^{s}\right)=\frac{350719 a^{2}}{276768 b}
$$

Suppose the hub player is unionized. We distinguish two cases.

[Case 1] $T \leq \frac{63 a}{275}$

For the unionized hub country:

$$
\begin{aligned}
U_{i}^{*}\left(g^{s}\right) & =\frac{(21 a+10 T)^{2}}{4900 b}, W_{i}^{*}\left(g^{s}\right)=\frac{a}{5}+\frac{2 T}{21}, \Pi_{i}^{*}\left(g^{s}\right)=\frac{3969 a^{2}+3780 a T+3350 T^{2}}{58800 b} \\
C S_{i}^{*}\left(g^{s}\right) & =\frac{169 a^{2}}{800 b}, C T_{i}^{*}\left(g^{s}\right)=0, S W_{i}^{*}\left(g^{s}\right)=\frac{1239 a^{2}+504 a T+260 T^{2}}{3360 b}
\end{aligned}
$$

For the unionized spoke country:

$$
\begin{aligned}
U_{i}^{*}\left(g^{s}\right) & =\frac{(21 a-10 T)^{2}}{4900 b}, W_{i}^{*}\left(g^{s}\right)=\frac{a}{5}-\frac{2 T}{21}, \Pi_{i}^{*}\left(g^{s}\right)=\frac{\left.3969 a^{2}-3780 a T+32750 T^{2}\right)}{58800 b} \\
C S_{i}^{*}\left(g^{s}\right) & =\frac{(13 a-5 T)^{2}}{800 b}, C T_{i}^{*}\left(g^{s}\right)=\frac{(7 a-15 T) T}{20 b}, S W_{i}^{*}\left(g^{s}\right)=\frac{1239 a^{2}+126 a T-475 T^{2}}{3360 b}
\end{aligned}
$$


For the non-unionized spoke country:

$$
\begin{aligned}
\Pi_{i}^{*}\left(g^{s}\right) & =\frac{147 a^{2}-140 a T+250 T^{2}}{400 b}, C S_{i}^{*}\left(g^{s}\right)=\frac{(13 a-5 T)^{2}}{800 b}, C T_{i}^{*}\left(g^{s}\right)=\frac{(63 a-275 T) T}{420 b} \\
S W_{i}^{*}\left(g^{s}\right) & =\frac{9723 a^{2}-6090 a T+25 T^{2}}{16800 b}
\end{aligned}
$$

and the global welfare is

$$
S W^{*}\left(g^{s}\right)=\frac{1053 a^{2}-140 a T-50 T^{2}}{800 b}
$$

[Case 2] $\frac{63 a}{275}<T \leq \frac{a}{4}$. Then, $X_{i k}^{*}\left(g^{s}(j)\right)=0, i \neq k$, when $i$ denotes the unionized spoke country.

For the unionized hub country:

$$
\begin{aligned}
U_{i}^{*}\left(g^{s}\right) & =\frac{13(22 a+7 T)^{2}}{62424 b}, W_{i}^{*}\left(g^{s}\right)=\frac{22 a+7 T}{102}, \Pi_{i}^{*}\left(g^{s}\right)=\frac{9302 a^{2}+4578 a T+6523 T^{2}}{124848 b} \\
C S_{i}^{*}\left(g^{s}\right) & =\frac{25(79 a-5 T)^{2}}{749088 b}, C T_{i}^{*}\left(g^{s}\right)=0, S W_{i}^{*}\left(g^{s}\right)=\frac{287341 a^{2}+55766 a T+47407 T^{2}}{749088 b}
\end{aligned}
$$

For the unionized spoke country:

$$
\begin{aligned}
U_{i}^{*}\left(g^{s}\right) & =\frac{(62 a+29 T)^{2}}{62424 b}, W_{i}^{*}\left(g^{s}\right)=\frac{62 a+29 T}{306}, \Pi_{i}^{*}\left(g^{s}\right)=\frac{\left.1922 a^{2}+1978 a T+1721 T^{2}\right)}{41616 b} \\
C S_{i}^{*}\left(g^{s}\right) & =\frac{(395 a-178 T)^{2}}{749088 b}, C T_{i}^{*}\left(g^{s}\right)=\frac{(217 a-434 T) T}{612 b} \\
S W_{i}^{*}\left(g^{s}\right) & =\frac{236749 a^{2}+200504 a T-458462 T^{2}}{749088 b}
\end{aligned}
$$

For the non-unionized spoke country:

$$
\begin{aligned}
\Pi_{i}^{*}\left(g^{s}\right) & =\frac{51894 a^{2}-56854 a T+63059 T^{2}}{124848 b}, C S_{i}^{*}\left(g^{s}\right)=\frac{49(26 a-T)^{2}}{187272 b} \\
C T_{i}^{*}\left(g^{s}\right) & =0, S W_{i}^{*}\left(g^{s}\right)=\frac{221930 a^{2}-175658 a T+189275 T^{2}}{374544 b}
\end{aligned}
$$

and the global welfare is

$$
S W^{*}\left(g^{s}\right)=\frac{322650 a^{2}-31682 a T-10835 T^{2}}{249696 b}
$$

The complete network.

For the unionized country:

$$
\begin{aligned}
U_{i}^{*}\left(g^{c}\right) & =\frac{9 a^{2}}{100 b}, W_{i}^{*}\left(g^{c}\right)=\frac{a}{5}, \Pi_{i}^{*}\left(g^{c}\right)=\frac{27 a^{2}}{400 b}, C S_{i}^{*}\left(g^{c}\right)=\frac{169 a^{2}}{800 b} \\
C T_{i}^{*}\left(g^{c}\right) & =0, S W_{i}^{*}\left(g^{c}\right)=\frac{59 a^{2}}{160 b}
\end{aligned}
$$

For the non-unionized country:

$$
\Pi_{i}^{*}\left(g^{c}\right)=\frac{147 a^{2}}{400 b}, C S_{i}^{*}\left(g^{c}\right)=\frac{169 a^{2}}{800 b}, C T_{i}^{*}\left(g^{c}\right)=0, S W_{i}^{*}\left(g^{c}\right)=\frac{463 a^{2}}{800 b}
$$


and the global welfare is

$$
S W^{*}\left(g^{c}\right)=\frac{1053 a^{2}}{800 b}
$$

\section{Appendix D: All countries are unionized}

The empty network.

$$
\begin{aligned}
U_{i}^{*}\left(g^{e}\right) & =\frac{(3 a-2 T)^{2}}{64 b}, W_{i}^{*}\left(g^{e}\right)=\frac{6 a-4 T}{24}, \Pi_{i}^{*}\left(g^{e}\right)=\frac{81 a-108 a T+548 T^{2}}{768 b} \\
C S_{i}^{*}\left(g^{e}\right) & =\frac{9(3 a-2 T)^{2}}{512 b}, C T_{i}^{*}\left(g^{e}\right)=\frac{(9 a-22 T) T}{24 b}, S W_{i}^{*}\left(g^{e}\right)=\frac{3(3 a-2 T)(23 a+6 T)}{512 b} \\
S W^{*}\left(g^{e}\right) & =\frac{9(3 a-2 T)(23 a+6 T)}{512 b}
\end{aligned}
$$

The partially connected network.

For a linked country:

$$
\begin{aligned}
U_{i}^{*}\left(g^{p}\right) & =\frac{(21 a-4 T)^{2}}{3136 b}, W_{i}^{*}\left(g^{p}\right)=\frac{21 a-4 T}{84}, \Pi_{i}^{*}\left(g^{p}\right)=\frac{9\left(147 a^{2}-56 a T+528 T^{2}\right)}{12544 b} \\
C S_{i}^{*}\left(g^{p}\right) & =\frac{(27 a-8 T)^{2}}{4608 b}, C T_{i}^{*}\left(g^{p}\right)=\frac{(63 a-200 T) T}{336 b}, S W_{i}^{*}\left(g^{p}\right)=\frac{13041 a^{2}-6368 T^{2}}{32256 b}
\end{aligned}
$$

For an isolated country:

$$
\begin{aligned}
U_{i}^{*}\left(g^{p}\right) & =\frac{(21 a-20 T)^{2}}{3136 b}, W_{i}^{*}\left(g^{p}\right)=\frac{21 a-20 T}{84}, \Pi_{i}^{*}\left(g^{p}\right)=\frac{3969 a^{2}-7560 a T+42800 T^{2}}{37632 b} \\
C S_{i}^{*}\left(g^{p}\right) & =\frac{(27 a-20 T)^{2}}{4608 b}, C T_{i}^{*}\left(g^{p}\right)=\frac{(21 a-60 T) T}{56 b} \\
S W_{i}^{*}\left(g^{p}\right) & =\frac{13041 a^{2}-10584 a T+9040 T^{2}}{32256 b}
\end{aligned}
$$

and the global welfare is

$$
S W^{*}\left(g^{p}\right)=\frac{1863 a^{2}-504 a T-176 T^{2}}{1536 b}
$$

The star network.

For the hub country:

$$
\begin{aligned}
U_{i}^{*}\left(g^{s}\right) & =\frac{9(7 a+2 T)^{2}}{3136 b}, W_{i}^{*}\left(g^{s}\right)=\frac{7 a+2 T}{28}, \Pi_{i}^{*}\left(g^{s}\right)=\frac{3969 a^{2}+2268 a T+1892 T^{2}}{37632 b} \\
C S_{i}^{*}\left(g^{s}\right) & =\frac{(27 a+2 T)^{2}}{4608 b}, C T_{i}^{*}\left(g^{s}\right)=0, S W_{i}^{*}\left(g^{s}\right)=\frac{13041 a^{2}+5292 a T+2020 T^{2}}{32256 b}
\end{aligned}
$$


For the spoke countries:

$$
\begin{aligned}
U_{i}^{*}\left(g^{s}\right) & =\frac{(21 a-10 T)^{2}}{3136 b}, W_{i}^{*}\left(g^{s}\right)=\frac{21 a-10 T}{84}, \Pi_{i}^{*}\left(g^{s}\right)=\frac{3969 a^{2}-3780 a T+21284 T^{2}}{37632 b} \\
C S_{i}^{*}\left(g^{s}\right) & =\frac{(27 a-10 T)^{2}}{4608 b}, C T_{i}^{*}\left(g^{s}\right)=\frac{(63 a-226 T) T}{336 b} \\
S W_{i}^{*}\left(g^{s}\right) & =\frac{13041 a^{2}-5292 a T-1724 T^{2}}{32256 b}
\end{aligned}
$$

and the global welfare is

$$
S W^{*}\left(g^{s}\right)=\frac{1863 a^{2}-252 a T-68 T^{2}}{1536 b}
$$

The complete network.

$$
\begin{aligned}
U_{i}^{*}\left(g^{c}\right) & =\frac{9 a^{2}}{64 b}, W_{i}^{*}\left(g^{c}\right)=\frac{a}{4}, \Pi_{i}^{*}\left(g^{c}\right)=\frac{27 a^{2}}{256 b}, C S_{i}^{*}\left(g^{c}\right)=\frac{81 a^{2}}{512 b} \\
C T_{i}^{*}\left(g^{c}\right) & =0, S W_{i}^{*}\left(g^{c}\right)=\frac{207 a^{2}}{512 b}, S W^{*}\left(g^{c}\right)=\frac{621 a^{2}}{512 b}
\end{aligned}
$$

\section{Appendix E: Proofs}

\section{Proof of Lemma 1.}

We analyze first the case in which all countries are non-unionized.

In such case, two countries in the empty network $g^{e}$ have a symmetric position. Since

$$
S W_{i}^{*}\left(g^{p}\right)=\frac{15 a^{2}+2 a T-11 T^{2}}{32 b}>\frac{(3 a-2 T)(5 a+2 T)}{32 b}=S W_{i}^{*}\left(g^{e}\right), \text { with } i \in N\left(g^{p}\right),
$$

for all $T<\frac{6 a}{7}$, it follows that $S W_{i}^{*}\left(g^{p}\right)>S W_{i}^{*}\left(g^{e}\right)$ and $S W_{j}^{*}\left(g^{p}\right)>S W_{j}^{*}\left(g^{e}\right)$ with $i j \in g^{p}$. Thus, any pair of countries in the empty network would like to form a bilateral free trade agreement.

Also two spoke countries in the star network $g^{s}$ have a symmetric position. Since

$$
S W_{i}^{*}\left(g^{c}\right)=\frac{15 a^{2}}{32 b}>\frac{15 a^{2}-6 a T-3 T^{2}}{32 b}=S W_{i}^{*}\left(g^{s}\right)
$$

for all $T>0$, with $i j \notin g^{s}$, it follows that $S W_{i}^{*}\left(g^{c}\right)>S W_{i}^{*}\left(g^{s}\right)$ and $S W_{j}^{*}\left(g^{c}\right)>S W_{j}^{*}\left(g^{s}\right)$ with $i j \notin g^{s}$. Thus, the two spoke countries in the star network would like to form a bilateral free trade agreement.

We analyze now the case in which two countries are non-unionized.

In such case, two non-unionized countries in the empty network $g^{e}$ have a symmetric position. 
(i) We consider first the case where $T \leq \frac{3 a}{14}$. Since

$$
S W_{i}^{*}\left(g^{p}(i j)\right)=\frac{5247 a^{2}-1140 a T-1868 T^{2}}{10368 b}>\frac{(3 a-2 T)(1749 a+274 T)}{10368 b}=S W_{i}^{*}\left(g^{e}\right),
$$

for all $T<\frac{64 a}{55}$, with $i j \in g^{p}$, it follows that $S W_{i}^{*}\left(g^{p}(i j)\right)>S W_{i}^{*}\left(g^{e}\right)$ and $S W_{j}^{*}\left(g^{p}(i j)\right)>$ $S W_{j}^{*}\left(g^{e}\right)$.

(ii) Next, we consider the case where $\frac{3 a}{14}<T \leq \frac{a}{4}$. Since

$$
S W_{i}^{*}\left(g^{p}(i j)\right)=\frac{5\left(61 a^{2}-28 a T+20 T^{2}\right)}{576 b}>\frac{(3 a-2 T)(1749 a+274 T)}{10368 b}=S W_{i}^{*}\left(g^{e}\right),
$$

for all $T>0$, with $i j \in g^{p}$, it follows that $S W_{i}^{*}\left(g^{p}(i j)\right)>S W_{i}^{*}\left(g^{e}\right)$ and $S W_{j}^{*}\left(g^{p}(i j)\right)>$ $S W_{j}^{*}\left(g^{e}\right)$.

Also two spoke non-unionized countries in the star network $g^{s}(k)$ have a symmetric position. Since

$$
S W_{i}^{*}\left(g^{c}\right)=\frac{583 a^{2}}{1152 b}>\frac{5247 a^{2}-1536 a T-872 T^{2}}{10368 b}=S W_{i}^{*}\left(g^{s}(k)\right)
$$

for all $T>0$, with $i j \notin g^{s}(k)$, it follows that $S W_{i}^{*}\left(g^{c}\right)>S W_{i}^{*}\left(g^{s}(k)\right)$ and $S W_{j}^{*}\left(g^{c}\right)>$ $S W_{j}^{*}\left(g^{s}(k)\right)$ with $i j \notin g^{s}(k)$.

We analyze now the case in which two countries are unionized.

In such case, two unionized countries in the empty network $g^{e}$ have a symmetric position. Since

$$
S W_{i}^{*}\left(g^{p}(i j)\right)=\frac{59 a^{2}+30 a T-55 T^{2}}{160 b}>\frac{(3 a-2 T)(177 a+122 T)}{1440 b}=S W_{i}^{*}\left(g^{e}\right)
$$

for all $T<\frac{258 a}{251}$, with $i j \in g^{p}$, it follows that $S W_{i}^{*}\left(g^{p}(i j)\right)>S W_{i}^{*}\left(g^{e}\right)$ and $S W_{j}^{*}\left(g^{p}(i j)\right)>$ $S W_{j}^{*}\left(g^{e}\right)$ with $i j \in g^{p}(i j)$.

Also two spoke unionized countries in the star network $g^{s}(k)$ have a symmetric position.

(i) We consider first the case where $T \leq \frac{9 a}{41}$. Since

$$
S W_{i}^{*}\left(g^{s}(k)\right)=\frac{531 a^{2}-258 a T-79 T^{2}}{1440 b}<\frac{59 a^{2}}{160 b}=S W_{i}^{*}\left(g^{c}\right)
$$

for all $T>0$, with $i j \notin g^{s}(k)$, it follows that $S W_{i}^{*}\left(g^{s}(k)\right)<S W_{i}^{*}\left(g^{c}\right)$ and $S W_{j}^{*}\left(g^{s}(k)\right)<$ $S W_{j}^{*}\left(g^{c}\right)$.

(ii) Next, we consider the case where $\frac{9 a}{41}<T \leq \frac{a}{4}$. Since

$$
S W_{i}^{*}\left(g^{s}(k)\right)=\frac{13807 a^{2}}{46128 b}<\frac{59 a^{2}}{160 b}=S W_{i}^{*}\left(g^{c}\right)
$$

with $i j \notin g^{s}(k)$, it follows that $S W_{i}^{*}\left(g^{s}(k)\right)<S W_{i}^{*}\left(g^{c}\right)$ and $S W_{j}^{*}\left(g^{s}(k)\right)<S W_{j}^{*}\left(g^{c}\right)$.

Finally, we analyze the case in which all countries are unionized. 
In such case, two countries in the empty network $g^{e}$ have a symmetric position. Since

$$
S W_{i}^{*}\left(g^{p}\right)=\frac{13041 a^{2}-6368 T^{2}}{32256 b}>\frac{3(3 a-2 T)(23 a+6 T)}{512 b}=S W_{i}^{*}\left(g^{e}\right), \text { with } i j \in g^{p},
$$

for all $T<\frac{1323 a}{1025}$, it follows that $S W_{i}^{*}\left(g^{p}\right)>S W_{i}^{*}\left(g^{e}\right)$ and $S W_{j}^{*}\left(g^{p}\right)>S W_{j}^{*}\left(g^{e}\right)$ with $i j \in g^{p}$.

Also two spoke countries in the star network $g^{s}$ have a symmetric position. Since

$$
S W_{i}^{*}\left(g^{c}\right)=\frac{207 a^{2}}{512 b}>\frac{13041 a^{2}-5292 a T-1724 T^{2}}{32256 b}=S W_{i}^{*}\left(g^{s}\right)
$$

for all $T>0$, with $i j \notin g^{s}$, it follows that $S W_{i}^{*}\left(g^{c}\right)>S W_{i}^{*}\left(g^{s}\right)$ and $S W_{j}^{*}\left(g^{c}\right)>S W_{j}^{*}\left(g^{s}\right)$ with $i j \notin g^{s}$.

\section{Proof of Lemma 2.}

\section{We analyze first the case in which two countries are non-unionized.}

In such case, the unionized country and any non-unionized country in the empty network $g^{e}$ have a symmetric position. Since

$$
S W_{i}^{*}\left(g^{p}\right)=\frac{415 a^{2}+132 a T-396 T^{2}}{1152 b}>\frac{(3 a-2 T)(1245 a+1186 T)}{10368 b}=S W_{i}^{*}\left(g^{e}\right), \text { with } i j \in g^{p},
$$

for all $T<\frac{15 a}{149}$, it follows that the unionized country only would like to form a link with a non-unionized country iff $T<\frac{15 a}{149}$.

Also the spoke unionized country and a spoke non-unionized country in the star network $g^{s}$ have a symmetric position.

(i) We consider first the case where $T \leq \frac{3 a}{16}$. Since

$$
S W_{i}^{*}\left(g^{c}\right)=\frac{583 a^{2}}{1152 b}>\frac{5247 a^{2}-3864 a T+136 T^{2}}{10368 b}=S W_{i}^{*}\left(g^{s}(j)\right)
$$

for all $T<\frac{483 a}{17}$, where $i, j$ represent the two non-unionized countries, $i \neq j$, and

$$
S W_{k}^{*}\left(g^{c}\right)=\frac{415 a^{2}}{1152 b}>\frac{3735 a^{2}-120 a T-1688 T^{2}}{10368 b}=S W_{k}^{*}\left(g^{s}(j)\right)
$$

for all $T>0$, with $k$ the unionized country, it follows that $S W_{i}^{*}\left(g^{c}\right)>S W_{i}^{*}\left(g^{s}\right)$ and $S W_{k}^{*}\left(g^{c}\right)>S W_{k}^{*}\left(g^{s}\right)$ with $i k \notin g^{s}$.

(ii) Next, we consider the case where $\frac{3 a}{16}<T \leq \frac{a}{4}$. Since

$$
S W_{i}^{*}\left(g^{c}\right)=\frac{583 a^{2}}{1152 b}>\frac{580 a^{2}-476 a T+613 T^{2}}{1152 b}=S W_{i}^{*}\left(g^{s}(j)\right)
$$

for all $T<0.783 a$, where $i, j$ represent the two non-unionized countries, $i \neq j$, and

$$
S W_{k}^{*}\left(g^{c}\right)=\frac{415 a^{2}}{1152 b}>\frac{1492 a^{2}+796 a T-2963 T^{2}}{4608 b}=S W_{k}^{*}\left(g^{s}(j)\right)
$$


for all $T>0$, with $k$ the unionized country, it follows that $S W_{i}^{*}\left(g^{c}\right)>S W_{i}^{*}\left(g^{s}\right)$ and $S W_{k}^{*}\left(g^{c}\right)>S W_{k}^{*}\left(g^{s}\right)$ with $i k \notin g^{s}$.

\section{We analyze next the case in which two countries are unionized.}

In such case, any unionized country and the non-unionized country in the empty network $g^{e}$ have a symmetric position. Since

$$
S W_{i}^{*}\left(g^{p}(i k)\right)=\frac{3717 a^{2}-294 a T-1921 T^{2}}{10080 b}<\frac{(3 a-2 T)(177 a+122 T)}{1440 b}=S W_{i}^{*}\left(g^{e}\right),
$$

for all $T>0$, when $i$ is any unionized country and $k$ is the non-unionized country, it follows that any unionized country never wants to form a link with the non-unionized country in the empty network.

Also a spoke unionized country and the spoke non-unionized country in the star network $g^{s}$ have a symmetric position.

(i) We consider first the case where $T \leq \frac{63 a}{275}$. Since

$$
S W_{i}^{*}\left(g^{c}\right)=\frac{59 a^{2}}{160 b}<\frac{1239 a^{2}+126 a T-475 T^{2}}{3360 b}=S W_{i}^{*}\left(g^{s}(j)\right)
$$

for all $T<\frac{126 a}{475}$, where $i, j$ represent the two unionized countries, $i \neq j$, it follows that the spoke unionized country does not want to form a link with the non-unionized spoke country.

(ii) Next, we consider the case where $\frac{63 a}{275}<T \leq \frac{a}{4}$. Since

$$
S W_{i}^{*}\left(g^{c}\right)=\frac{59 a^{2}}{160 b}>\frac{236749 a^{2}+200504 a T-458462 T^{2}}{749088 b}=S W_{i}^{*}\left(g^{s}(j)\right)
$$

for all $T>0$, where $i, j$ represent the two unionized countries, $i \neq j$, and

$$
S W_{k}^{*}\left(g^{c}\right)=\frac{463 a^{2}}{800 b}>\frac{221930 a^{2}-175658 a T+189275 T^{2}}{374544 b}=S W_{k}^{*}\left(g^{s}(j)\right)
$$

for all $0.0304<T<0.898 a$, it follows that both the unionized and the non-unionized spoke countries would like to form a link between them.

\section{Proof of Proposition 1.}

By Lemma 1, the empty network $g^{e}$ and the star network $g^{s}$ are never pairwise stable since two symmetric countries of the same type always want to form a bilateral free trade agreement. Thus, the complete network $g^{c}$ is always pairwise stable, since no pair of countries $i$ and $j$ have incentives to delete their link $i j \in g^{c}$.

The partially connected network $g^{p}$ is never pairwise stable because the isolated country and any of the two linked countries have incentives to sign a free trade agreement, i.e., $S W_{i}^{*}\left(g^{p}\right)<S W_{i}^{*}\left(g^{s}\right)$ and $S W_{j}^{*}\left(g^{p}\right)<S W_{j}^{*}\left(g^{s}\right)$ with $i j \notin g^{p}, i j \in g^{s}$, and $j \notin N\left(g^{p}\right)$. Since

$$
S W_{j}^{*}\left(g^{p}\right)=\frac{15 a^{2}-12 a T+16 T^{2}}{32 b}<\frac{15 a^{2}-6 a T-3 T^{2}}{32 b}=S W_{j}^{*}\left(g^{s}\right)
$$


for all $T<\frac{6 a}{19}$, and

$$
S W_{i}^{*}\left(g^{p}\right)=\frac{15 a^{2}+2 a T-11 T^{2}}{32 b}<\frac{15 a^{2}+8 a T+4 T^{2}}{32 b}=S W_{i}^{*}\left(g^{s}\right),
$$

for all $T>0, g^{p}$ is never pairwise stable.

\section{Proof of Proposition 2.}

By Lemma 1, the empty network $g^{e}$ and the star network $g^{s}(k)$ are never stable because two symmetric non-unionized countries have always incentives to form a bilateral trade agreement. By Lemma 2, the star networks $g^{s}(i)$ and $g^{s}(j)$ are never pairwise stable because the spoke unionized country and the spoke non-unionized country have incentives to form a bilateral free trade agreement. Thus, the complete network $g^{c}$ is always pairwise stable.

By Lemma 2, the partial networks $g^{p}(i k)$ and $g^{p}(j k)$ are not pairwise stable for $\frac{15 a}{149}<$ $T \leq \frac{a}{4}$ because the unionized country would have incentives to delete his link with the non-unionized country. Moreover, for $T \leq \frac{15 a}{149}$, the partial networks $g^{p}(i k)$ and $g^{p}(j k)$ are not pairwise stable because the non-unionized countries have incentives to form a link moving to the star network $g^{s}(i)$ or $g^{s}(j)$. Indeed,

$$
S W_{i}^{*}\left(g^{p}(j k)\right)=\frac{583 a^{2}-600 a T+576 T^{2}}{1152 b}<\frac{5247 a^{2}-3864 a T+136 T^{2}}{10368 b}=S W_{i}^{*}\left(g^{s}(j)\right)
$$

for all $T<\frac{192 a}{631}$, when $i$ is the isolated non-unionized country in $g^{p}(j k)$, and

$$
S W_{j}^{*}\left(g^{p}(j k)\right)=\frac{11\left(53 a^{2}+12 a T-36 T^{2}\right)}{1152 b}<\frac{5247 a^{2}+2724 a T+1036 T^{2}}{10368 b}=S W_{j}^{*}\left(g^{s}(j)\right)
$$

for all $T>0$, when $j$ is the linked non-unionized country in $g^{p}(j k)$. Then, the network $g^{p}(j k)$ (and $\left.g^{p}(i k)\right)$ is not pairwise stable.

Finally, the partially connected network $g^{p}(i j)$ is pairwise stable if and only if $\frac{5 a}{167}<$ $T \leq \frac{a}{4}$ because the unionized country has no incentives to sign a free trade agreement with any of the linked non-unionized countries. To show that the network $g^{p}(i j)$ is pairwise stable, we have to show that $S W_{i}^{*}\left(g^{p}(i j)\right)>S W_{i}^{*}\left(g^{s}(i)\right)$, or $S W_{k}^{*}\left(g^{p}(i j)\right)>S W_{k}^{*}\left(g^{s}(i)\right)$ for all values of $T$ in the interval.

(i) We consider first the case where $T \leq \frac{3 a}{16}$. Since

$$
S W_{k}^{*}\left(g^{p}(i j)\right)=\frac{5\left(747 a^{2}-48 a T+464 T^{2}\right)}{10368 b}>\frac{3735 a^{2}-120 a T-1688 T^{2}}{10368 b}=S W_{k}^{*}\left(g^{S}(i)\right) ;
$$

for all $T>\frac{5 a}{167}$, and

$$
S W_{i}^{*}\left(g^{p}(i j)\right)=\frac{5247 a^{2}-1140 a T-1868 T^{2}}{10368 b}<\frac{5247 a^{2}+2724 a T+1036 T^{2}}{10368 b}=S W_{i}^{*}\left(g^{s}(i)\right),
$$


for all $T>0$, it follows that $g^{p}(i j)$ is pairwise stable if and only if $\frac{5 a}{167}<T \leq \frac{3 a}{16}$. Otherwise, for $T \leq \frac{5 a}{167}$, the network $g^{p}(i j)$ is not pairwise stable because any non-unionized linked country and the unionized isolated country will have incentives to form a link between them moving to the star network $g^{s}(i)$ or $g^{s}(j)$.

(ii) Second, we consider the case where $\frac{3 a}{16}<T \leq \frac{3 a}{14}$. Since

$$
S W_{k}^{*}\left(g^{p}(i j)\right)=\frac{5\left(747 a^{2}-48 a T+464 T^{2}\right)}{10368 b}>\frac{1492 a^{2}+796 a T-2963 T^{2}}{4608 b}=S W_{k}^{*}\left(g^{s}(i)\right) ;
$$

for all $T>0$, and

$$
S W_{i}^{*}\left(g^{p}(i j)\right)=\frac{5247 a^{2}-1140 a T-1868 T^{2}}{10368 b}<\frac{2452 a^{2}+716 a T+341 T^{2}}{4608 b}=S W_{i}^{*}\left(g^{s}(i)\right),
$$

for all $T>0$, it follows that $g^{p}(i j)$ is pairwise stable for $\frac{3 a}{16}<T \leq \frac{3 a}{14}$.

(iii) Finally, we consider the case where $\frac{3 a}{14}<T \leq \frac{a}{4}$. Since

$$
S W_{k}^{*}\left(g^{p}(i j)\right)=\frac{(331 a-298 T)(a+2 T)}{1152 b}>\frac{1492 a^{2}+796 a T-2963 T^{2}}{4608 b}=S W_{k}^{*}\left(g^{s}(i)\right) ;
$$

for all $T>0.214 a$, and

$$
S W_{i}^{*}\left(g^{p}(i j)\right)=\frac{5\left(61 a^{2}-28 a T+20 T^{2}\right)}{576 b}<\frac{2452 a^{2}+716 a T+341 T^{2}}{4608 b}=S W_{i}^{*}\left(g^{s}(i)\right),
$$

for all $T<4.01 a, i=B, C$, it follows that $g^{p}(i j)$ is pairwise stable for $\frac{3 a}{14}<T \leq \frac{a}{4}$.

\section{Proof of Proposition 3.}

As shown by Lemma 1 , the empty network $g^{e}$ and the star network $g^{s}(k)$ are never stable because two symmetric unionized countries have always incentives to form a bilateral trade agreement. By Lemma 2, the partial networks $g^{p}(i k)$ and $g^{p}(j k)$ are never pairwise stable because the unionized country would have incentives to delete his link with the non-unionized country. By Lemma 2, the star networks $g^{s}(i)$ and $g^{s}(j)$ are not pairwise stable for $\frac{63 a}{275}<T \leq \frac{a}{4}$ because the spoke unionized country and the spoke non-unionized country have incentives to form a bilateral free trade agreement. Thus, the complete network $g^{c}$ is always pairwise stable for $\frac{63 a}{275}<T \leq \frac{a}{4}$.

Moreover, the star networks $g^{s}(i)$ and $g^{s}(j)$ are not pairwise stable for $T \leq T^{\prime} \simeq 0.089 a$, because the unionized hub country has incentives to delete his link with the non-unionized spoke country moving to the partial network $g^{p}(i j)$. Let $T^{\prime} \simeq 0.089 a$ be the value of $T$ for which $S W_{i}^{*}\left(g^{p}(i j)\right)=S W_{i}^{*}\left(g^{s}(i)\right)$. Since

$$
S W_{k}^{*}\left(g^{p}(i j)\right)=\frac{463 a^{2}-580 a T+400 T^{2}}{800 b}<\frac{9723 a^{2}-6090 a T+25 T^{2}}{16800 b}=S W_{k}^{*}\left(g^{s}(i)\right)
$$

for all $T<\frac{1218 a}{1675}$, and

$$
S W_{i}^{*}\left(g^{p}(i j)\right)=\frac{59 a^{2}+30 a T-55 T^{2}}{160 b}>\frac{1239 a^{2}+504 a T+260 T^{2}}{3360 b}=S W_{i}^{*}\left(g^{s}(i)\right),
$$


for $T \leq T^{\prime} \simeq 0.089 a$, then, $g^{s}(i)$ and $g^{s}(j)$ are not pairwise stable for $T \leq T^{\prime} \simeq 0.089 a$. Thus, $g^{p}(i j)$ is pairwise stable if and only if $T \leq T^{\prime}$ because no unionized country has incentive to delete the link between them.

Finally, the star networks $g^{s}(i)$ and $g^{s}(j)$ are pairwise stable if and only if $T^{\prime}<T \leq \frac{63 a}{275}$. For such values of $T$ both the unionized hub country and the non-unionized spoke country have not incentives to delete the link between them. Moreover, the spoke unionized country does not want to form a link with the spoke non-unionized country and does not want to delete his link with the hub unionized country. That is,

$$
S W_{i}^{*}\left(g^{c}\right)=\frac{59 a^{2}}{160 b}<\frac{1239 a^{2}+126 a T-475 T^{2}}{3360 b}=S W_{i}^{*}\left(g^{s}(j)\right)
$$

for all $T<\frac{126 a}{475}$, and

$$
S W_{i}^{*}\left(g^{p}(j k)\right)=\frac{3717 a^{2}-1428 a T+2480 T^{2}}{10080 b}<\frac{1239 a^{2}+126 a T-475 T^{2}}{3360 b}=S W_{i}^{*}\left(g^{s}(j)\right)
$$

for all $T<\frac{1806 a}{3905}, i \neq j$. Then, $g^{s}(i)$ and $g^{s}(j)$ are pairwise stable if and only if $T^{\prime} \leq T \leq \frac{9 a}{41}$.

\section{Proof of Proposition 4.}

By Lemma 1, the empty network $g^{e}$ and the star network $g^{s}$ are never pairwise stable since two symmetric countries of the same type always want to form a bilateral free trade agreement. Thus, the complete network $g^{c}$ is always pairwise stable, since no pair of countries $i$ and $j$ have incentives to delete their link $i j \in g^{c}$.

The partially connected network $g^{p}$ is never pairwise stable because the isolated country and any of the two linked countries have incentives to sign a free trade agreement, i.e., $S W_{i}^{*}\left(g^{p}\right)<S W_{i}^{*}\left(g^{s}\right)$ and $S W_{j}^{*}\left(g^{p}\right)<S W_{j}^{*}\left(g^{s}\right)$ with $i j \notin g^{p}, i j \in g^{s}$, and $j \notin N\left(g^{p}\right)$. Since

$$
S W_{j}^{*}\left(g^{p}\right)=\frac{13041 a^{2}-10584 a T+9040 T^{2}}{32256 b}<\frac{13041 a^{2}-5292 a T-1724 T^{2}}{32256 b}=S W_{j}^{*}\left(g^{s}\right)
$$

for all $T<\frac{147 a}{299}$, and

$$
S W_{i}^{*}\left(g^{p}\right)=\frac{13041 a^{2}-6368 T^{2}}{32256 b}<\frac{13041 a^{2}+5292 a T+2020 T^{2}}{32256 b}=S W_{i}^{*}\left(g^{s}\right)
$$

for all $T>0, g^{p}$ is never pairwise stable.

\section{Proof of Proposition 5.}

Proof: We consider the four different settings.

\section{[1.] All countries are non-unionized.}


Comparing the aggregate social welfare of the different networks we have

$$
\begin{gathered}
S W^{*}\left(g^{c}\right)=\frac{45 a^{2}}{32 b}>S W^{*}\left(g^{s}\right)=\frac{45 a^{2}-4 a T-2 T^{2}}{32 b} \\
S W^{*}\left(g^{s}\right)=\frac{45 a^{2}-4 a T-2 T^{2}}{32 b}>S W^{*}\left(g^{p}\right)=\frac{45 a^{2}-8 a T-6 T^{2}}{32 b} \\
S W^{*}\left(g^{p}\right)=\frac{45 a^{2}-8 a T-6 T^{2}}{32 b}>S W^{*}\left(g^{e}\right)=\frac{3(3 a-2 T)(5 a+2 T)}{32 b}
\end{gathered}
$$

for all $T \leq \frac{a}{4}$. Thus, $S W^{*}\left(g^{c}\right)>S W^{*}\left(g^{s}\right)>S W^{*}\left(g^{p}\right)>S W^{*}\left(g^{e}\right)$ and aggregate social welfare is increasing with the number of links.

\section{[2.] Country $\mathrm{k}$ is unionized, countries $\mathbf{i}$ and $\mathbf{j}$ are non-unionized.}

We should consider three cases.

Case 1. $T<\frac{3 a}{16}$

Comparing the aggregate social welfare of the different networks we have

$$
\begin{gathered}
S W^{*}\left(g^{c}\right)=\frac{527 a^{2}}{384 b}>S W^{*}\left(g^{s}(i)\right)=\frac{4743 a^{2}-420 a T-172 T^{2}}{3456 b} \\
S W^{*}\left(g^{s}(i)\right)=\frac{4743 a^{2}-420 a T-172 T^{2}}{3456 b}>S W^{*}\left(g^{s}(k)\right)=\frac{4743 a^{2}-588 a T-268 T^{2}}{3456 b} \\
S W^{*}\left(g^{s}(k)\right)=\frac{4743 a^{2}-588 a T-268 T^{2}}{3456 b}>S W^{*}\left(g^{p}(i j)\right)=\frac{4743 a^{2}-840 a T-472 T^{2}}{3456 b} \\
S W^{*}\left(g^{p}(i j)\right)=\frac{4743 a^{2}-840 a T-472 T^{2}}{3456 b}>S W^{*}\left(g^{p}(i k)\right)=\frac{527 a^{2}-112 a T-72 T^{2}}{384 b} \\
S W^{*}\left(g^{p}(i k)\right)=\frac{527 a^{2}-112 a T-72 T^{2}}{384 b}>S W^{*}\left(g^{e}\right)=\frac{17(3 a-2 T)(93 a+34 T)}{3456 b} \\
\text { Thus, } S W^{*}\left(g^{c}\right)>S W^{*}\left(g^{s}(i)\right)=S W^{*}\left(g^{s}(j)\right)>S W^{*}\left(g^{s}(k)\right)>S W^{*}\left(g^{p}(i j)\right)>S W^{*}\left(g^{p}(i k)\right) \\
=S W^{*}\left(g^{p}(j k)\right)>S W^{*}\left(g^{e}\right) \text { and aggregate social welfare is increasing with the number of }
\end{gathered}
$$
links.

Case 2. $\frac{3 a}{16}<T<\frac{3 a}{14}$

Comparing the aggregate social welfare of the different networks we have

$$
\begin{gathered}
S W^{*}\left(g^{c}\right)=\frac{527 a^{2}}{384 b}>S W^{*}\left(g^{s}(i)\right)=\frac{3132 a^{2}-196 a T-85 T^{2}}{2304 b} \\
S W^{*}\left(g^{s}(i)\right)=\frac{3132 a^{2}-196 a T-85 T^{2}}{2304 b}>S W^{*}\left(g^{s}(k)\right)=\frac{4743 a^{2}-588 a T-268 T^{2}}{3456 b} \\
S W^{*}\left(g^{s}(k)\right)=\frac{4743 a^{2}-588 a T-268 T^{2}}{3456 b}>S W^{*}\left(g^{p}(i j)\right)=\frac{4743 a^{2}-840 a T-472 T^{2}}{3456 b} \\
S W^{*}\left(g^{p}(i j)\right)=\frac{4743 a^{2}-840 a T-472 T^{2}}{3456 b}>S W^{*}\left(g^{p}(i k)\right)=\frac{527 a^{2}-112 a T-72 T^{2}}{384 b} \\
S W^{*}\left(g^{p}(i k)\right)=\frac{527 a^{2}-112 a T-72 T^{2}}{384 b}>S W^{*}\left(g^{e}\right)=\frac{17(3 a-2 T)(93 a+34 T)}{3456 b}
\end{gathered}
$$


Thus, $S W^{*}\left(g^{c}\right)>S W^{*}\left(g^{s}(i)\right)=S W^{*}\left(g^{s}(j)\right)>S W^{*}\left(g^{s}(k)\right)>S W^{*}\left(g^{p}(i j)\right)>S W^{*}\left(g^{p}(i k)\right)$ $=S W^{*}\left(g^{p}(j k)\right)>S W^{*}\left(g^{e}\right)$ and aggregate social welfare is increasing with the number of links.

Case 3. $\frac{3 a}{14}<T<\frac{a}{4}$

Comparing the aggregate social welfare of the different networks we have

$$
\begin{gathered}
S W^{*}\left(g^{c}\right)=\frac{527 a^{2}}{384 b}>S W^{*}\left(g^{s}(i)\right)=\frac{3132 a^{2}-196 a T-85 T^{2}}{2304 b} \\
S W^{*}\left(g^{s}(i)\right)=\frac{3132 a^{2}-196 a T-85 T^{2}}{2304 b}>S W^{*}\left(g^{s}(k)\right)=\frac{4743 a^{2}-588 a T-268 T^{2}}{3456 b} \\
S W^{*}\left(g^{s}(k)\right)=\frac{4743 a^{2}-588 a T-268 T^{2}}{3456 b}>S W^{*}\left(g^{p}(i j)\right)=\frac{(33 a-14 T)(47 a+14 T)}{1152 b} \\
S W^{*}\left(g^{p}(i j)\right)=\frac{(33 a-14 T)(47 a+14 T)}{1152 b}>S W^{*}\left(g^{p}(i k)\right)=\frac{527 a^{2}-112 a T-72 T^{2}}{384 b} \\
S W^{*}\left(g^{p}(i k)\right)=\frac{527 a^{2}-112 a T-72 T^{2}}{384 b}>S W^{*}\left(g^{e}\right)=\frac{17(3 a-2 T)(93 a+34 T)}{3456 b}
\end{gathered}
$$

Thus, $S W^{*}\left(g^{c}\right)>S W^{*}\left(g^{s}(i)\right)=S W^{*}\left(g^{s}(j)\right)>S W^{*}\left(g^{s}(k)\right)>S W^{*}\left(g^{p}(i j)\right)>S W^{*}\left(g^{p}(i k)\right)$ $=S W^{*}\left(g^{p}(j k)\right)>S W^{*}\left(g^{e}\right)$ and aggregate social welfare is increasing with the number of links.

[3.] Countries $\mathbf{i}$ and $\mathbf{j}$ are unionized, country $\mathrm{k}$ is non-unionized.

We should consider three cases.

Case 1. $T<\frac{9 a}{41}$

Comparing the aggregate social welfare of the different networks we have

$$
\begin{gathered}
S W^{*}\left(g^{c}\right)=\frac{1083 a^{2}}{800 b}>S W^{*}\left(g^{s}(k)\right)=\frac{3159 a^{2}-252 a T-86 T^{2}}{2400 b} \\
S W^{*}\left(g^{s}(k)\right)=\frac{3159 a^{2}-252 a T-86 T^{2}}{2400 b}>S W^{*}\left(g^{s}(i)\right)=\frac{1053 a^{2}-140 a T-50 T^{2}}{800 b} \\
S W^{*}\left(g^{s}(i)\right)=\frac{1053 a^{2}-140 a T-50 T^{2}}{800 b}>S W^{*}\left(g^{p}(i k)\right)=\frac{1053 a^{2}-224 a T-102 T^{2}}{800 b} \\
S W^{*}\left(g^{p}(i k)\right)=\frac{1053 a^{2}-224 a T-102 T^{2}}{800 b}>S W^{*}\left(g^{p}(i j)\right)=\frac{1053 a^{2}-280 a T-150 T^{2}}{800 b} \\
S W^{*}\left(g^{p}(i j)\right)=\frac{1053 a^{2}-280 a T-150 T^{2}}{800 b}>S W^{*}\left(g^{e}\right)=\frac{13(3 a-2 T)(81 a+26 T)}{2400 b}
\end{gathered}
$$

Thus, $S W^{*}\left(g^{c}\right)>S W^{*}\left(g^{s}(k)\right)>S W^{*}\left(g^{s}(i)\right)=S W^{*}\left(g^{s}(j)\right)>S W^{*}\left(g^{p}(i k)\right)=S W^{*}\left(g^{p}(j k)\right)$ $>S W^{*}\left(g^{p}(i j)\right)>S W^{*}\left(g^{e}\right)$ and aggregate social welfare is increasing with the number of links.

Case 2. $\frac{9 a}{41}<T<\frac{63 a}{275}$

Comparing the aggregate social welfare of the different networks we have

$$
S W^{*}\left(g^{c}\right)=\frac{1083 a^{2}}{800 b}>S W^{*}\left(g^{s}(i)\right)=\frac{1053 a^{2}-140 a T-50 T^{2}}{800 b}
$$




$$
\begin{gathered}
S W^{*}\left(g^{s}(i)\right)=\frac{1053 a^{2}-140 a T-50 T^{2}}{800 b}>S W^{*}\left(g^{s}(k)\right)=\frac{350719 a^{2}}{276768 b} \\
S W^{*}\left(g^{s}(k)\right)=\frac{350719 a^{2}}{276768 b}>S W^{*}\left(g^{p}(i k)\right)=\frac{1053 a^{2}-224 a T-102 T^{2}}{800 b} \\
S W^{*}\left(g^{p}(i k)\right)=\frac{1053 a^{2}-224 a T-102 T^{2}}{800 b}>S W^{*}\left(g^{p}(i j)\right)=\frac{1053 a^{2}-280 a T-150 T^{2}}{800 b} \\
S W^{*}\left(g^{p}(i j)\right)=\frac{1053 a^{2}-280 a T-150 T^{2}}{800 b}>S W^{*}\left(g^{e}\right)=\frac{13(3 a-2 T)(81 a+26 T)}{2400 b}
\end{gathered}
$$

Thus, $S W^{*}\left(g^{c}\right)>S W^{*}\left(g^{s}(i)\right)=S W^{*}\left(g^{s}(j)\right)>S W^{*}\left(g^{s}(k)\right)>S W^{*}\left(g^{p}(i k)\right)=S W^{*}\left(g^{p}(j k)\right)$ $>S W^{*}\left(g^{p}(i j)\right)>S W^{*}\left(g^{e}\right)$ and aggregate social welfare is increasing with the number of links.

Case 3. $\frac{63 a}{275}<T<\frac{a}{4}$

Comparing the aggregate social welfare of the different networks we have

$$
\begin{gathered}
S W^{*}\left(g^{c}\right)=\frac{1083 a^{2}}{800 b}>S W^{*}\left(g^{s}(k)\right)=\frac{350719 a^{2}}{276768 b} \\
S W^{*}\left(g^{s}(k)\right)=\frac{350719 a^{2}}{276768 b}>S W^{*}\left(g^{s}(i)\right)=\frac{322650 a^{2}-31682 a T-10835 T^{2}}{249696 b} \\
S W^{*}\left(g^{s}(i)\right)=\frac{322650 a^{2}-31682 a T-10835 T^{2}}{249696 b}>S W^{*}\left(g^{p}(i k)\right)=\frac{1053 a^{2}-224 a T-102 T^{2}}{800 b} \\
S W^{*}\left(g^{p}(i k)\right)=\frac{1053 a^{2}-224 a T-102 T^{2}}{800 b}>S W^{*}\left(g^{p}(i j)\right)=\frac{1053 a^{2}-280 a T-150 T^{2}}{800 b} \\
S W^{*}\left(g^{p}(i j)\right)=\frac{1053 a^{2}-280 a T-150 T^{2}}{800 b}>S W^{*}\left(g^{e}\right)=\frac{13(3 a-2 T)(81 a+26 T)}{2400 b}
\end{gathered}
$$

Thus, $S W^{*}\left(g^{c}\right)>S W^{*}\left(g^{s}(k)\right)>S W^{*}\left(g^{s}(i)\right)=S W^{*}\left(g^{s}(j)\right)>S W^{*}\left(g^{p}(i k)\right)=S W^{*}\left(g^{p}(j k)\right)$ $>S W^{*}\left(g^{p}(i j)\right)>S W^{*}\left(g^{e}\right)$ and aggregate social welfare is increasing with the number of links.

\section{[4.] All countries are unionized.}

Comparing the aggregate social welfare of the different networks we have

$$
\begin{gathered}
S W^{*}\left(g^{c}\right)=\frac{621 a^{2}}{512 b}>S W^{*}\left(g^{s}\right)=\frac{1863 a^{2}-252 a T-68 T^{2}}{1536 b} \\
S W^{*}\left(g^{s}\right)=\frac{1863 a^{2}-252 a T-68 T^{2}}{1536 b}>S W^{*}\left(g^{p}\right)=\frac{1863 a^{2}-504 a T-176 T^{2}}{1536 b} \\
S W^{*}\left(g^{p}\right)=\frac{1863 a^{2}-504 a T-176 T^{2}}{1536 b}>S W^{*}\left(g^{e}\right)=\frac{9(3 a-2 T)(23 a+6 T)}{512 b}
\end{gathered}
$$

for all $T \leq \frac{a}{4}$. Thus, $S W^{*}\left(g^{c}\right)>S W^{*}\left(g^{s}\right)>S W^{*}\left(g^{p}\right)>S W^{*}\left(g^{e}\right)$ and aggregate social welfare is increasing with the number of links.

Finally, Corollary 1 and Corollary 2 follow directly from the proofs of Proposition 1, Proposition 2, Proposition 3 and Proposition 4. 


\section{References}

[1] Anderson, S.P., M.P. Donsimoni and J.J. Gabszewicz, "Is International Trade Profitable to Oligopolistic Industries?," International Economic Review 30(4), 725-733 (1989).

[2] Bagwell, K. and R.W. Staiger, "An Economic Theory of GATT," American Economic Review 89, 215-248 (1999).

[3] Bhagwati, J., "Regionalism and Multilateralism: An Overview," in J. de Melo and A. Panagariya, eds., New Dimensions in Regional Integration, World Bank and Cambridge University Press, Cambridge, UK, 22-51 (1993).

[4] Bala, V. and S. Goyal, "A Non-Cooperative Model of Network Formation," Econometrica 68, 1181-1231 (2000).

[5] Belleflamme, P. and F. Bloch, "Market Sharing Agreements and Collusive Networks," International Economic Review 45(2), 387-411 (2004).

[6] Bond, E.W. and C. Syropoulos, "The Size of Trading Blocs, Market Power and World Welfare Effects," Journal of International Economics 40, 411-437 (1996).

[7] Chang, W. and L.A. Winters, "How Regional Blocs affect Excluded Countries: the Price Effects of Mercosur," American Economic Review 92, 889-904 (2002).

[8] Cordella, T., "Trade Liberalization and Oligopolistic Industries: A Welfare Appraisal," Recherches Economiques de Louvain 59(3), 355-363 (1993).

[9] Deardorff, A.V. and R.M. Stern, in A.V. Deardorff and R.S. Stern, eds., Analytical and Negotiating Issues in the Global Trading System, The University of Michigan Press, Ann Arbor (1997).

[10] Ethier, W.J., "Regionalism in a Multilateral World," Journal of Political Economy 106, 1214-1245 (1998).

[11] Furusawa, T. and H. Konishi, "Free Trade Networks," Working Paper N 548, Boston College, Mass (2002).

[12] Furusawa, T. and H. Konishi, "Free Trade Networks with Transfers," Japanese Economic Review 56, 144-164 (2005).

[13] Goyal, S. and S. Joshi, "Bilateralism and Free Trade," forthcoming in International Economic Review (2005). 
[14] Grafe, F. and A. Mauleon, "Externalities and Free Trade Agreements," Annales d'Economie et de Statistique 59, 63-88 (2000).

[15] Herings, P.J.J., A. Mauleon and V. Vannetelbosch, "Rationalizability for Social Environments," Games and Economic Behavior 49(1), 135-156 (2004).

[16] Jackson, M.O., "The Stability and Efficiency of Economic and Social Networks," in Networks and Groups: Models of Strategic Formation, edited by B. Dutta and M.O. Jackson, Springer-Verlag: Heidelberg (2003).

[17] Jackson, M.O., "A Survey of Models of Network Formation: Stability and Efficiency," in Group Formation in Economics: Networks, Clubs and Coalitions, edited by G. Demange and M. Wooders, Cambridge University Press (2005).

[18] Jackson, M.O. and A. Watts, "The Existence of Pairwise Stable Networks," Seoul Journal of Economics 14, 299-321 (2001).

[19] Jackson, M.O. and A. Watts, "The Evolution of Social and Economic Networks," Journal of Economic Theory 71, 44-74 (2002).

[20] Jackson, M.O. and A. Wolinsky, "A Strategic Model of Social and Economic Networks," Journal of Economic Theory 71, 44-74 (1996).

[21] Jones, S.R.G., "The Role of Negotiators in Union-Firm Bargaining," Canadian Journal of Economics 22(3), 630-642 (1989).

[22] Kennan, J. and R. Riezman, "Optimal Tariff Equilibria with Customs Unions," Canadian Journal of Economics 23, 70-83 (1990).

[23] Krishna, P., "Regionalism and Multilateralism: A Political Economy Approach," The Quarterly Journal of Economics 113, 227-251 (1998).

[24] Krugman, P.R., "Is Bilateralism Bad?," in E. Helpman and A. Razin, eds., International Trade and Trade Policy MIT Press, Cambridge, 9-23 (1991).

[25] Huizinga, H., "International Market Integration and Union Wage Bargaining," Scandinavian Journal of Economics 95, 249-255 (1993).

[26] Levy, P.I., "A Political-Economic Analysis of Free-Trade Agreements," American Economic Review 87, 506-519 (1997).

[27] Mauleon, A. and V. Vannetelbosch, "Strategic Union Delegation and Strike Activity," Canadian Journal of Economics 38(1), 149-173 (2005). 
[28] Naylor, R., "International Trade and Economic Integration when Labour Markets are Generally Unionized," European Economic Review 42, 1251-1267 (1998).

[29] Ornelas, E., "Endogenous Free Trade Agreements and the Multilateral Trading System," Journal of International Economics 67, 471-497 (2005a).

[30] Ornelas, E., "Trade Creating Free Trade Areas and the Undermining of Multilateralism," European Economic Review 49, 1717-1735 (2005b).

[31] Yi, S.S., "Endogenous Formation of Customs Unions Under Imperfect Competition: Open Regionalism is Good," Journal of International Economics 41, 153-177 (1996). 
Département des Sciences Économiques de l'Université catholique de Louvain

Institut de Recherches Économiques et Sociales

Place Montesquieu, 3

1348 Louvain-la-Neuve, Belgique 